\title{
Lusioersily
}

\section{Simulation and experimental validation of solar radiation distribution on the absorber of a line-axis asymmetric compound parabolic concentrator}

Muhumuza, R., Zacharopoulos, A., Mondol, J., Smyth, M., Pugsley, A., \& McGee, J. (2020). Simulation and experimental validation of solar radiation distribution on the absorber of a line-axis asymmetric compound parabolic concentrator. Solar Energy, 198, 36-52. https://doi.org/10.1016/j.solener.2020.01.033

Link to publication record in Ulster University Research Portal

Published in:
Solar Energy

Publication Status:

Published (in print/issue): 01/03/2020

DOI:

10.1016/j.solener.2020.01.033

\section{Document Version}

Author Accepted version

\section{General rights}

Copyright for the publications made accessible via Ulster University's Research Portal is retained by the author(s) and / or other copyright owners and it is a condition of accessing these publications that users recognise and abide by the legal requirements associated with these rights.

\section{Take down policy}

The Research Portal is Ulster University's institutional repository that provides access to Ulster's research outputs. Every effort has been made to ensure that content in the Research Portal does not infringe any person's rights, or applicable UK laws. If you discover content in the Research Portal that you believe breaches copyright or violates any law, please contact pure-support@ulster.ac.uk. 
Simulation and experimental validation of solar radiation distribution on the absorber of a line-axis asymmetric compound parabolic concentrator

\author{
Ronald Muhumuza ${ }^{1, a, b}$, Aggelos Zacharopoulos ${ }^{\mathrm{a}}$, Jayanta Deb Mondol ${ }^{\mathrm{a}}$, Mervyn Smyth ${ }^{\mathrm{a}}$, \\ Adrian Pugsley ${ }^{\mathrm{a}}$, Jade McGee ${ }^{\mathrm{a}}$ \\ ${ }^{a}$ Centre for Sustainable Technologies, Belfast School of Architecture and the Built \\ Environment, Ulster University, Newtownabbey BT37 0QB, Northern Ireland, UK \\ ${ }^{b}$ Faculty of Engineering, Department of Agro-processing engineering, Busitema University, \\ P.O. Box 236, Tororo, Uganda
}

\title{
Abstract
}

This paper reports the development and application of a new practical photovoltaic (PV) cells based device to measure the solar radiation flux produced by non-imaging Compound Parabolic Concentrators (CPCs) on cylindrical absorbers. The flexible experimental device comprises 12 discrete miniature PV panels that measure solar radiation on the surface of a cylindrical absorber. The device has been used to evaluate the performance of an asymmetric CPC system and results validated with a computer-based Ray Tracing Model. The study attained significant agreement between outdoor results of the experimental device and results of the ray tracing simulation with a difference of $<9 \%$ in optical efficiencies. The non-imaging reflector illuminates a targeted section of the absorber of a horizontal east-west thermal diode Integrated Collector Storage Solar Water Heater. During outdoor testing, the experiments indicated a local concentration ratio reaching 1.4 suns on the targeted section of the absorber vessel surface for incidence angles $-30^{\circ} \leq \theta_{i} \leq 30^{\circ}$, confirming technical suitability of the asymmetric CPC for deployment in locations at equatorial latitudes.

Keywords: Solar cogeneration; Flux distribution; CPC; optical efficiency; PV cells; ray tracing

\section{Nomenclature}

AM Air Mass

ANR Average Number of Reflections

CPC Compound Parabolic Concentrator

\footnotetext{
${ }^{1}$ Corresponding author.

E-mail address: muhumuza-r@ulster.ac.uk (R. Muhumuza), a.zacharopoulos@ulster. ac.uk (A.Zacharopoulos),jd.mondol@ulster.ac.uk (J. Deb Mondol), m.smyth1@ulster.ac.uk
} 
Concentration Ratio

$30 \mathrm{c}-\mathrm{Si}$

crystalline Silicon

31

Centre for Sustainable Technologies

32

ICSSWH Integrated Collector Storage Solar Water Heater

$33 \mathrm{I}-\mathrm{V}$

Current-Voltage

$34 \quad \mathrm{RTM}$

Ray Tracing Model

35 STC

Standard Testing Condition

$36 \quad \mathrm{~A}_{\mathrm{ap}}$

Aperture area of the prototype $\left(\mathrm{m}^{2}\right)$

$37 \quad A_{a b s}$

Surface area of the thermal diode ICSSWH receiver/absorber $\left(\mathrm{m}^{2}\right)$

$38 \theta_{i}$

Angle of incidence on the aperture of the solar collector (degree)

$39 \varnothing$

Rotation angle defining the inverted involute profile (radians)

$40 x$

Abscissa (x-axis) coordinate of the inverted involute profile ( $\mathrm{mm})$

$41 y$

Ordinate (y-axis) coordinate of the inverted involute profile $(\mathrm{mm})$

$42 \quad R_{1}$

Radius of the inner vessel (storage tank) of the thermal diode ICSSWH (mm)

$43 \quad R_{2}$

Radius of the outer vessel (absorber) of the thermal diode ICSSWH (mm)

$44 \quad C R$

Concentration Ratio (dimensionless)

$45 \quad G$

Total solar radiation incident on any plane $\left(\mathrm{W} / \mathrm{m}^{2}\right)$

$46 \quad G_{\mathrm{abs}}$

Total solar radiation on the absorber $\left(\mathrm{W} / \mathrm{m}^{2}\right)$

$47 \quad G_{\text {ap }}$

Total solar radiation on the collector aperture $\left(\mathrm{W} / \mathrm{m}^{2}\right)$

$48 G_{\text {ref }}$

Total solar radiation at a reference position $\left(\mathrm{W} / \mathrm{m}^{2}\right)$

$49 \quad I_{\mathrm{SC}}$

Short-circuit current (A)

$50 \quad I_{\text {peak }}$

Peak current (A)

$51 \quad I_{\mathrm{SC}, \mathrm{abs}}$

Short-circuit current measurement on the absorber (A)

$52 \quad I_{\mathrm{SC}, \mathrm{ap}}$

Short-circuit current measurement on the aperture (A)

$53 k$

Uncertainty coverage factor multiplier (dimensionless)

$54 \partial_{G}$

Sensitivity of the pyranometer $\left(\mu \mathrm{V} / \mathrm{W} \mathrm{m}^{2}\right)$

$55 \quad V_{\text {pyra }}$

Signal voltage of the pyranometer measured by a handheld digital multimeter $(\mathrm{mV})$

\section{Introduction}

The Asymmetric Formed Reflector with Integrated Collector and Storage (AFRICaS) system previously reported in Muhumuza et al. (2019a) is a novel combination of new and conventional solar technologies in a Solar Energy Cogeneration (SEC) concept capable of 
producing photovoltaic (PV) electricity and low temperature heat (up to $100{ }^{\circ} \mathrm{C}$ ). The design employs readily available solar technology to provide affordable modern energy for lowincome off-grid households in developing countries and to increase solar energy collection potential per unit area relative to conventional solar collectors. It is a scalable modular unit, deployable as a ground or roof mounted installation. Fig. 1 shows the general framework of the AFRICaS SEC prototype. It combines a standard PV subsystem, a solar water heater subsystem and their related energy storage functions. The solar water heater subsystem is a horizontal thermal diode Integrated Collector Storage Solar Water Heater (ICSSWH) with cylindrical vessels (Muhumuza et al., 2019b; Pugsley et al., 2019) set within an East-West lineaxis asymmetric non-imaging involute reflector. The asymmetric involute reflector fits the description of Compound Parabolic Concentrators (CPCs), a collective definition of a variety of useful non-imaging reflectors with and without parabolic sections (Winston, 2016; Widyolar et al., 2017). Section 2.1 describes the rationale for the selection of the reflector profile in the current research.

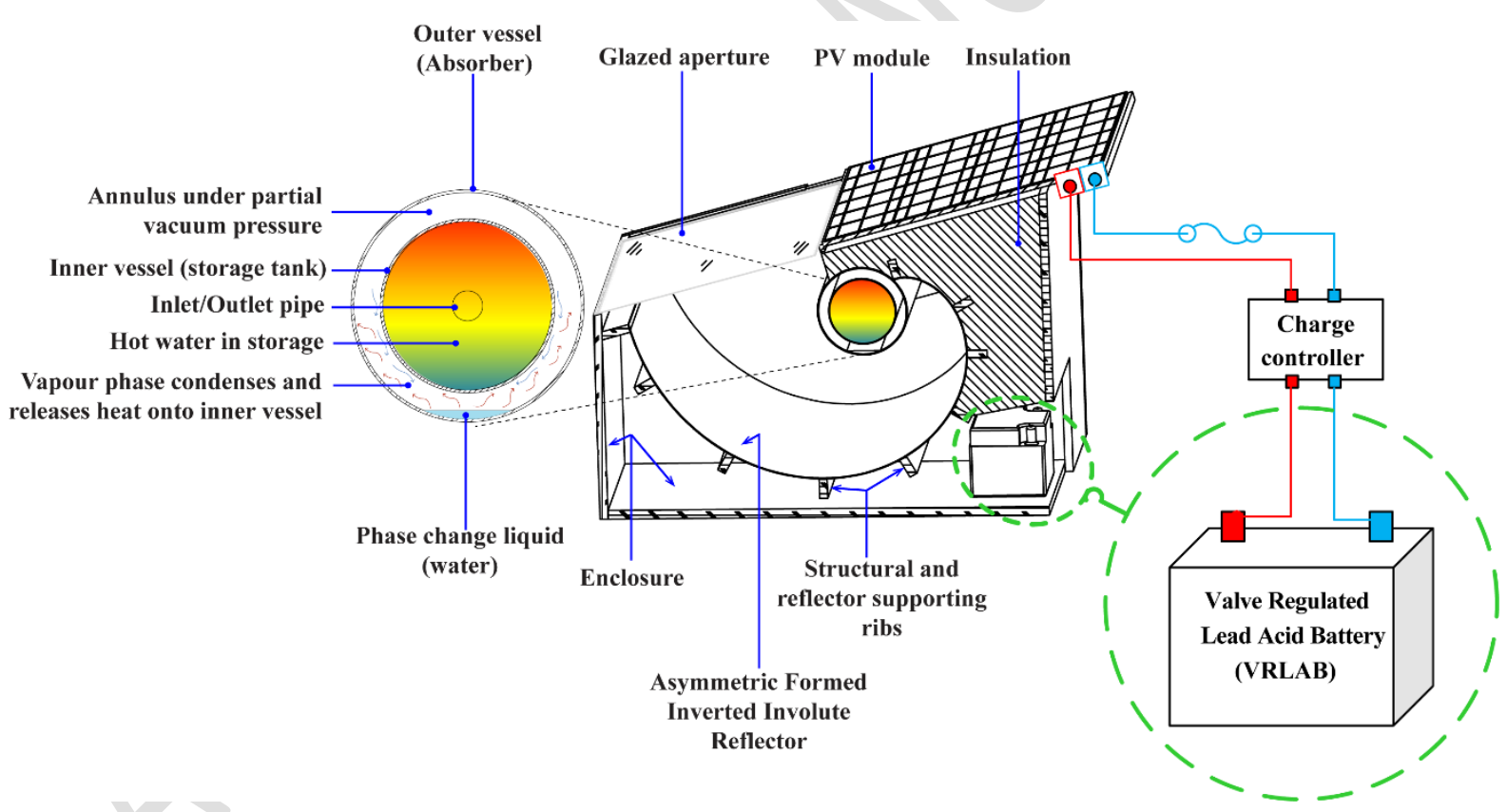

Fig. 1. System concept of the Asymmetric Formed Reflector with Integrated Collector and Storage (AFRICaS) Solar Energy Cogeneration (SEC) prototype (Muhumuza et al., 2019a)

The design of non-imaging reflectors in line-axis solar thermal and PV collectors finds three important limitations (Tabor, 1984), namely: a) material cost due to excessive reflector size, b) hotspots on the absorber due to uneven solar radiation flux distribution, and c) stationary systems require high acceptance angles resulting in a low Concentration Ratio (CR). CR refers to the ratio of the aperture area to the absorber area and is an approximate factor by which the 
reflector increases the solar radiation flux incident on the absorber surface (Duffie and Beckman, 2013). A high geometrical CR in non-imaging reflectors narrows the acceptance angle (i.e., the system's field of view of incident solar radiation), resulting in the need for periodic single and/or two-axis sun tracking (Horta et al., 2016; Kalogirou, 2016). While the reflector is often truncated to manage cost and the acceptance angle reduced to increase the $\mathrm{CR}$, the problem of uneven solar radiation flux distribution is inherent in many practical designs of non-imaging reflectors, leading to a collective consequence of non-uniform illumination of the absorber.

Non-uniform illumination is the unintended result of using non-imaging reflectors and creates high temperature zones on the absorber. While high thermal conductivity materials may overcome such hot zones on solar thermal absorbers, the resulting impact on efficiency in PV absorbers is problematic. Thus, the determination of solar radiation distribution on absorber surfaces is an essential component of realizing optimal non-imaging reflector designs in solar energy collectors. Literature reports many interesting non-imaging concentrator topics including:- a general comparison of solar concentrators (Rabl, 1976a), line-axis CPCs optical and thermal analysis (Norton et al., 1991), static designs for bifacial receivers (Benitez et al., 1999), concepts in stationary and passive applications (Madala and Boehm, 2017); design principles and recent technology advances (Tian et al., 2018), and combined elements or optical surfaces (Ma et al., 2019). Non-imaging reflectors are devices which concentrate solar radiation onto a receiver without producing an image of the light source. Their design utilizes extreme angular rays (or edge-rays), so that rays near the axis are out-of-focus, but all are still collected (O'Gallagher, 2008) resulting in a wide angular field of view in symmetric and asymmetric stationary systems for a given geometric CR. This research employs computer simulation and detailed experimental techniques to determine the optical performance of the asymmetric CPC reflector in the AFRICaS prototype.

Past studies developed theoretical and experimental methods to predict the distribution of solar radiation flux on receivers in concentrating systems with non-imaging reflectors. Theoretical literature exists employing various ray-tracing techniques including: graphical sketching and elaborate two dimensional (2D) and three dimensional (3D) ray-tracing simulations. Waghmare and Gulhane (2016) carried out a graphical ray tracing procedure, building on the work of Riveros and Oliva (1986), through a 2D Computer Aided Design approach to obtain the optimal placement of the absorber in a CPC structure. Guiqiang et al (2013) performed 
optical ray tracing analysis of a lens-walled CPC using optical software (LightTools) that imports the model of the CPC reflector profile designed using 3D Computer Aided Design software . Many other scholars (Zacharopoulos et al., 2000; Zacharopoulos, 2001; Sarmah et al., 2011; Yurchenko et al., 2015; Ustaoglu et al., 2016; Paul, 2019) employed elaborate simulations that consider Fresnel formulas, optical properties of air, transparent media, and specular properties of reflector surfaces. Others (Rabl, 1976b; Souliotis and Tripanagnostopoulos, 2008; Souliotis et al., 2019) performed detailed optical assessments of CPCs through a theoretical evaluation of Average Number of Reflections (ANR) as an alternative to the ray tracing approach.

Zacharopoulos et al (1996) performed optical analysis of four different absorber-envelope configurations in a CPC using a ray tracing model (RTM). The RTM considered diffuse and beam solar radiation whereby diffuse solar radiation modelling evaluated the effect of three skyward angular distributions (Prapas et al., 1987), i.e., isotropic, cosine, and hybrid Gaussian. Regardless of the specific RTM, prudent research also conducts a practical validation of theoretically determined solar radiation flux maps through a suitable experimental procedure. Smyth et al (1999b) employed thermocouples to predict solar radiation flux mapping in CPC systems with flat and cylindrical thermal absorbers. Other experimental studies employed commercial variants of PV cells (photodetectors) to establish solar radiation flux distribution measurements on absorber surfaces such as the silicon PIN photodiode (Simon and Kalinka, 2005) used by Adsten et al (2004) and Hatwaambo et al (2008).

Standard PV cells can enable the design of custom devices to determine solar radiation flux distribution on absorber surfaces in the laboratory. Scholars (Zacharopoulos et al., 2012; Paul et al., 2013) employed isolated PV cells in a configured CPC prototype to determine the quantity and distribution of solar radiation intercepting the absorber by correlating the short circuit current measured at the aperture of the CPC and absorber. Bhowmik and Kandpal (1988) used PV cells to characterise solar radiation flux on a triangular absorber in a linear solar concentrator. Guiqiang et al (2013) used PV cells to determine solar radiation flux distribution on the absorber in CPC concepts with mirror and lens walled surfaces by observing variations in Fill Factor. However, the majority of past experimental work considered standard PV cells to determine solar radiation flux distribution on absorbers with planar surfaces. in cylindrical absorbers. Cylindrical absorbers are prominent in concentrating solar thermal 
collectors but cylindrical PV concepts (Hiraki et al., 2012) are also emerging. The present work develops a new experimental device to determine solar radiation flux distribution and CR. This device is new in a sense that it extends the PV cell method of past scholars who investigated flux distributions on flat absorbers (Zacharopoulos et al., 2012; Paul et al., 2013) and applies it to a cylindrical absorber. The experimental method is similar to that used by past scholars in a sense that it utilises short circuit current measurements to determine geometric CR.

\section{Asymmetric CPC design, construction and methods}

\subsection{Asymmetric CPC design}

Recent research (Muhumuza et al., 2019b) found that a poor field of view of solar radiation in a basic horizontal configuration of a thermal diode ICSSWH with cylindrical vessels constrains heat transfer to the absorber zone where the Heat Transfer Fluid (HTF) Phase Change Material (PCM) resides. This is because the solar radiation reaching the desired absorber zone (denoted "CDE" on Fig. 2a) is insufficient, resulting in suboptimal operation of the thermal diode. Pugsley et al (2019) provides a clear technical description of the operation of such thermal diodes. Insufficient solar radiation in the desired absorber zone reduces evaporation and vapour mass transfer rates within the thermal diode resulting in increased absorber surface heat loss and reduced rate of heat transfer into the inner vessel (storage tank). Fig. 2b shows that a suitable reflector design could increase solar radiation in the desired absorber zone, thereby increasing evaporation of the working fluid and the rate of latent heat transfer to the inner storage vessel.

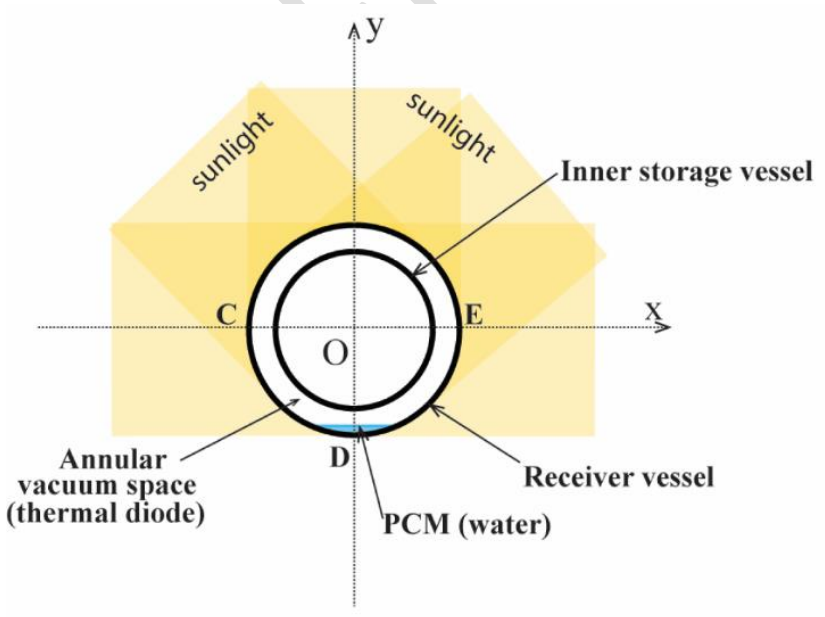

a

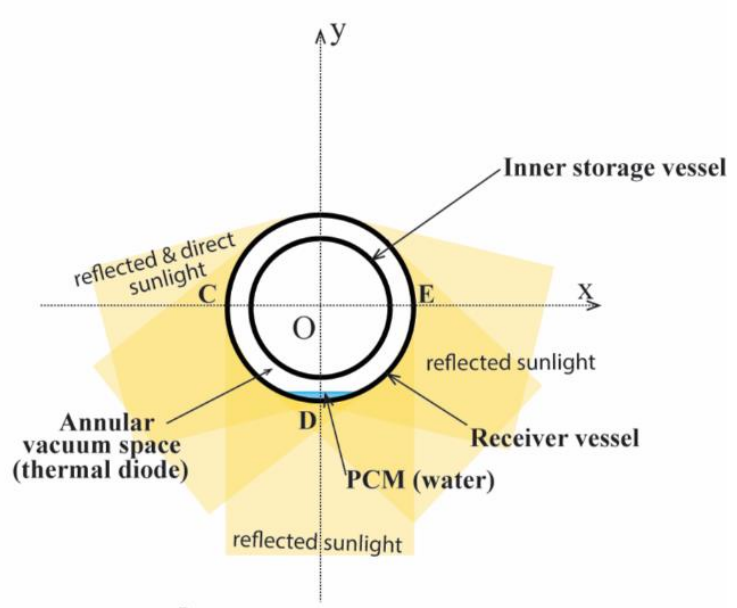

b 
Fig. 2. A basic cylindrical thermal diode ICSSWH (Muhumuza et al., 2019b) (a) receives poor sunlight in the desired absorber zone ' $\mathrm{CDE}$ ' interfacing the Phase Change Material (PCM) heat transfer fluid, (b) a suitable reflector can divert sunlight to the desired zone.

Fig. 3a shows the selected untruncated asymmetric CPC reflector profile PB of an inverted involute curve. The reflector provides a significant volume of hot air trap (convectionsuppressing cavity) near the targeted region of the absorber as shown in Fig. 3b. Past research (Tripanagnostopoulos and Yianoulis, 1992; Tripanagnostopoulos et al., 2000, 2002; Souliotis et al., 2011) highlighted the benefit of having a hot air trap adjacent to the absorber in cavities of reverse asymmetric reflector designs. It substantially reduces convection heat transfer from the absorber to the ambient particularly for single tank cylindrical solar collectors, which is beneficial for the overall heat retention performance of the thermal diode ICSSWH.

a

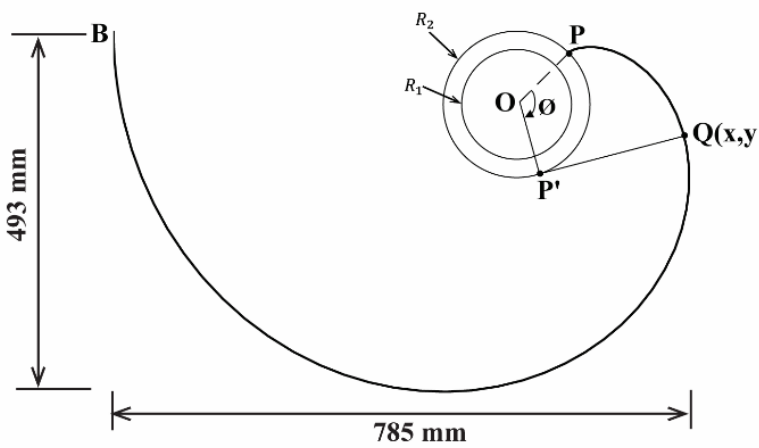

$\mathbf{b}$

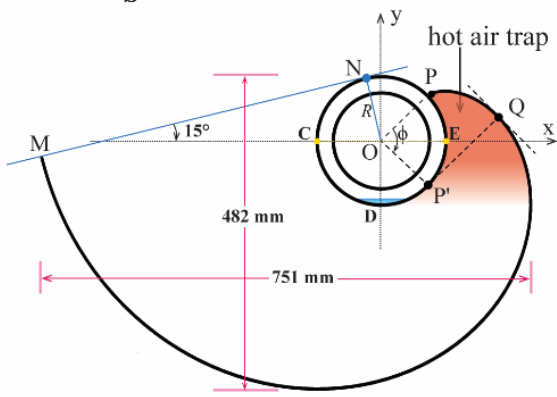

Fig. 3. Geometry showing (a) the selected untruncated asymmetric CPC profile and (b) the truncated asymmetric CPC structure that provides solar radiation around the absorber area NCDP'EP with a hot air trap near the targeted absorber surface denoted "CDE".

The following description focuses on the truncated asymmetric CPC profile shown in Fig. $3 \mathrm{~b}$. The reflector profile is a circle's involute curve (Chaves, 2016; Guichard et al., 2019) and originates at $\mathrm{P}$ in contact with the absorber surface whereby $\mathrm{OP}$ makes an angle of $45^{\circ}$ with OE to achieve a significant volume of stagnant hot air. The tangent at $\mathrm{P}^{\prime}$ on the absorber remains perpendicular to the tangent of the circle's involute curve at their intersection at $\mathrm{Q} . \mathrm{P}^{\prime}$ signals that point $\mathrm{P}$ is a moving point, which traverses the circumference of the absorber while defining different lengths of the absorber tangent $\mathrm{P}^{\prime} Q$ for different $Q(x, y)$ coordinates of the involute curve. A rotation angle of $\emptyset=\frac{5 \pi}{3}$ radians measured from OP truncates the reflector to minimise reflector material cost and defines the aperture $\mathrm{MN}$ at a tilt angle of $15^{\circ}$ with the horizontal allowing rainwater runoff to minimise soiling of the glass cover. For applications in equatorial latitudes (up to $35^{\circ}$ north and south of the equator), a tilt angle of $15^{\circ}$ allows operation of the AFRICaS prototype in a fixed position while keeping the solar radiation 
incident on the aperture near the optimal value. By slightly oversizing the receiver or slightly undersizing the circle's involute curve, most reflected light should reach the receiver after one or two reflections. Geometrical interpretation derives Eq. (1) as the parametric equation of the truncated asymmetric CPC,

$$
\begin{aligned}
& x=\frac{R}{\sqrt{2}}[(1+\emptyset) \sin \emptyset+(1-\emptyset) \cos \emptyset] \\
& y=\frac{R}{\sqrt{2}}[(1+\emptyset) \cos \emptyset-(1-\emptyset) \sin \emptyset]
\end{aligned} \text { for } 0 \leq \emptyset \leq \frac{5 \pi}{3}
$$

where $R$ is the radius (in $\mathrm{mm}$ ) and $\varnothing$ is the rotation angle (in radians) from OP. A radius of $R=R_{2}=100 \mathrm{~mm}$ (the radius of the outer cylindrical vessel in the current study) creates an optical cavity depth and width of $482 \mathrm{~mm}$ and $751 \mathrm{~mm}$, respectively. The fabricated prototype has an aperture width $\mathrm{MN}=459 \mathrm{~mm}$ and an aperture length of $981 \mathrm{~mm}$, resulting in an aperture surface area of $A_{a p}=0.45 \mathrm{~m}^{2}$. Considering the illuminated surface area of the absorber $\mathrm{NCDP}^{\prime} \mathrm{EP}$ of $\mathrm{A}_{\mathrm{abs}}=0.46 \mathrm{~m}^{2}$, the reflector profile has a design geometric $C R=\mathrm{A}_{\mathrm{ap}} / \mathrm{A}_{\mathrm{abs}}=$ $0.98 \approx 1$. This is not considered as concentration (Hadjiat et al., 2018), but it achieves illumination of the targeted zone $\mathrm{CDE}$ on the absorber surface without the need for sun tracking.

\subsection{Materials, construction and methods}

Outdoor and indoor experiments employed PV cells to measure solar radiation flux on the absorber surface in order to verify results of the results from the ray tracing simulation. Sections 2.2.1 and 2.2.2 describe fabrication, preparation and utilization of the new device of miniature PV cell panels employed for indoor and outdoor validation experiments. The number of measurement positions around the cylindrical absorber determines the smoothness of the determined experimental solar radiation flux profile. The experimental plan adopted 12 measurement positions of equal arc lengths around the circumference of the targeted section of the absorber. A smooth experimental flux profile is necessary in validating results from the $2 \mathrm{D}$ RTM but a judicious choice ensures a less laborious experiment. Similarly, the 2D RTM was prepared to produce results corresponding to the 12 experimental positions. Fig. 4 illustrates the solar radiation flux measurement positions around the absorber that comprise 12 equal arc lengths. Also shown, is the specification of experimental incidence angles in the experimental and ray tracing methodology. The experimental measurements were taken central to the longitudinal axis of the absorber, at about $490 \mathrm{~mm}$ from either end of the absorber in order to 

RTM.

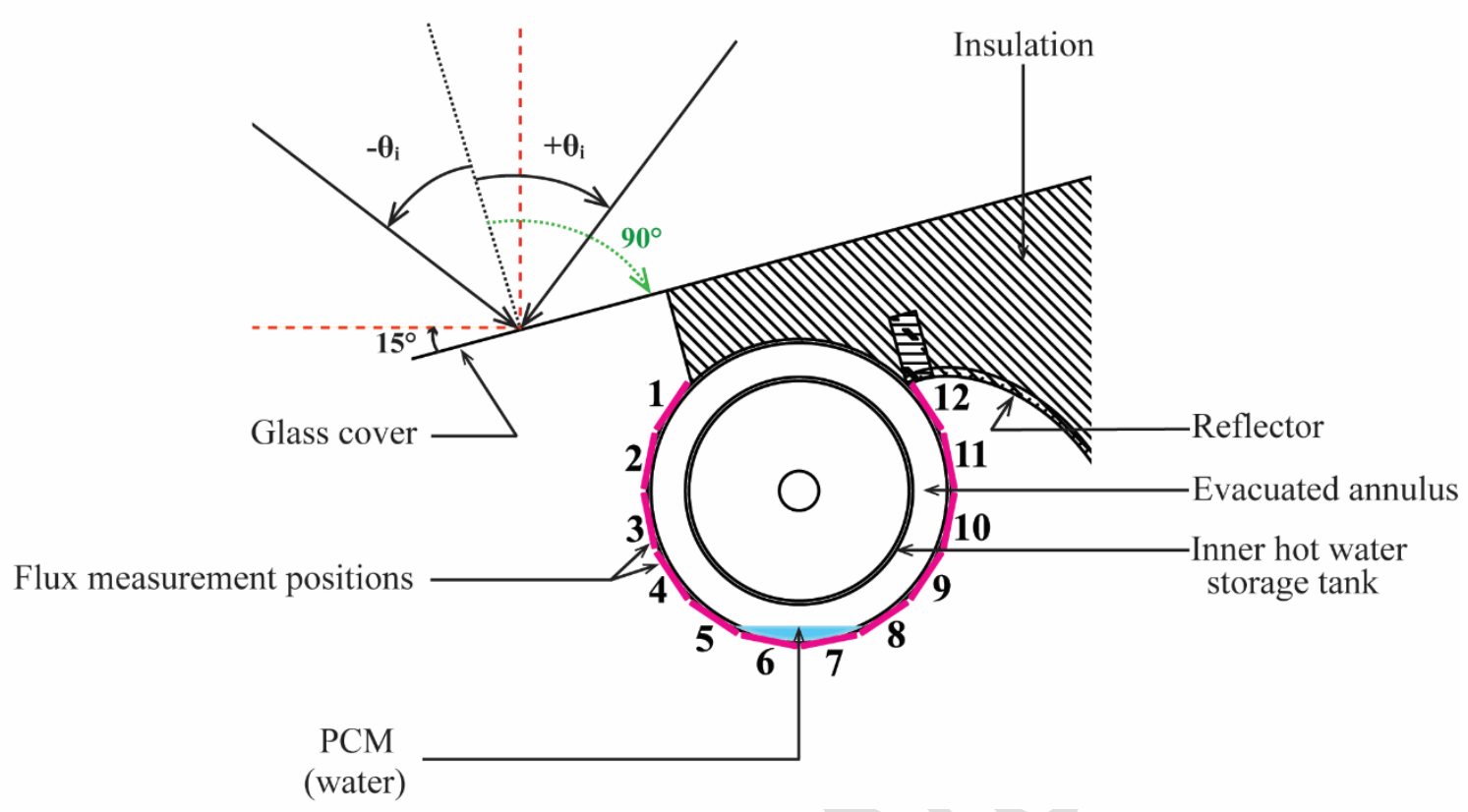

Fig. 4. The 12 arc lengths of flux measurement positions around the desired absorber region and the definition of incidence angles in the RTM and the experiment.

\subsubsection{Device fabrication and selection of suitable electrical conductors}

The new fabricated device consists of 12 discrete miniature PV panels to measure short circuit current around the cylindrical absorber according to the experimental scheme in Fig. 4. The PV cell strips are BP Solar Saturn crystalline silicon (c-Si) measuring $109 \mathrm{~mm}$ long $\times$ $9 \mathrm{~mm}$ wide and $0.4 \mathrm{~mm}$ thick. Green et al (1988) and Bruton et al (2003) describe the specific features of the BP Solar Saturn crystalline silicon PV cells and their laboratory performance in a 16 PV cell panel fabricated using larger area $7 \mathrm{~cm}$ long $\times 7 \mathrm{~cm}$ wide PV cells. Parallel connection of the PV cells in each miniature panel ensured the production of a measurable amount of current from any available solar radiation.

Fig. 5 shows the dimensions and components of each fabricated miniature PV panel. Each miniature PV panel consisted of three strips of PV cells connected in parallel in a manual soldering process. Soldering of the PV cell strips employed appropriate lengths of tinned copper ribbons measuring $2.5 \mathrm{~mm}$ wide and $0.2 \mathrm{~mm}$ thick in cross-sectional area, using recommended soldering temperatures. Overall, each complete miniature PV panel measured $120 \mathrm{~mm}$ long $\times 39 \mathrm{~mm}$ wide and $2.5 \mathrm{~mm}$ thick with the width considered tangential to the absorber circumference. A $2.5 \mathrm{~mm}$ thick Perspex substrate provided the support base for the 
soldered PV cell strips using double-sided adhesive tape. The exposed circumferential length of the desired region of the absorber is $471 \mathrm{~mm}$ and resulted in an approximate arc length of $39 \mathrm{~mm}$ for each miniature PV panel.

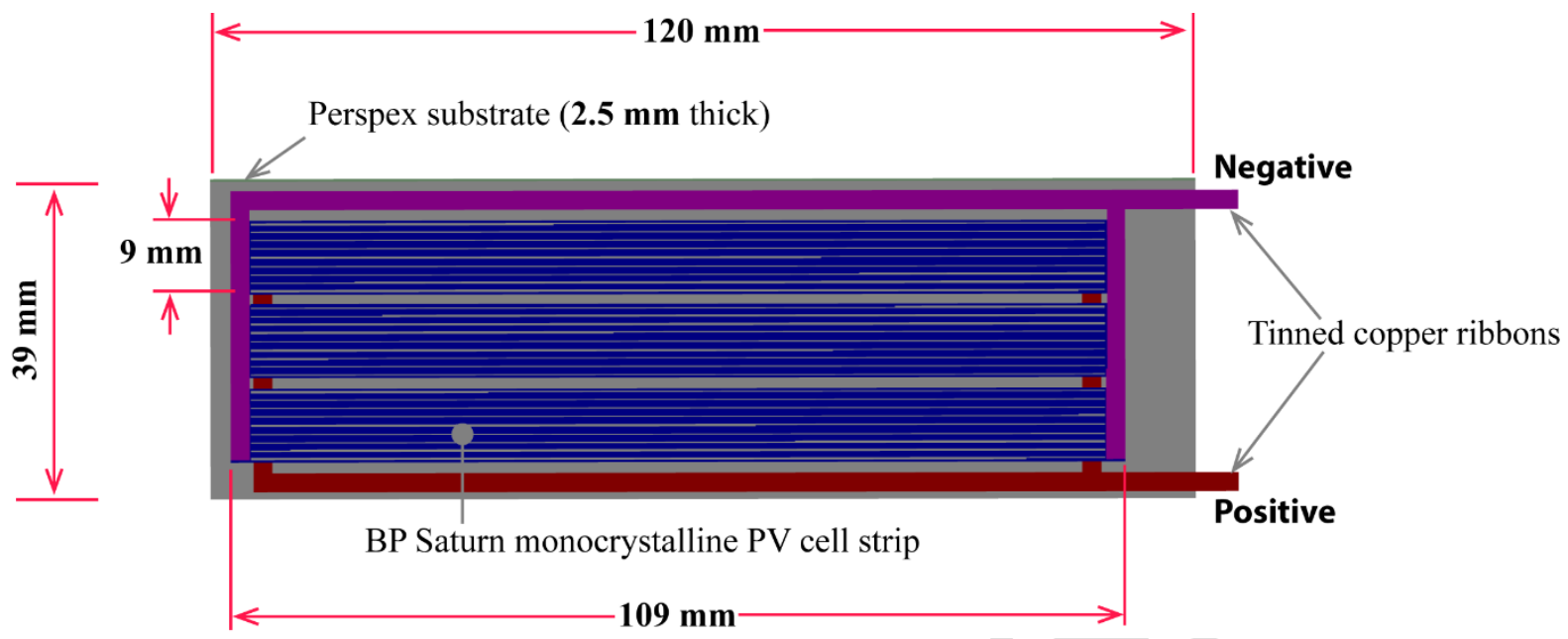

Fig. 5. Schematic structure of one of the fabricated miniature PV panels consisting of three BP Saturn monocrystalline PV cell strips (each $109 \mathrm{~mm}$ long x $9 \mathrm{~mm}$ wide and $0.4 \mathrm{~mm}$ thick) connected in parallel using tinned copper ribbons $(2.5 \mathrm{~mm}$ wide $\mathrm{x} 0.2 \mathrm{~mm}$ thick) and attached on a Perspex substrate support (120 mm long x $39 \mathrm{~mm}$ wide and $2.5 \mathrm{~mm}$ thick) using double sided adhesive tape

The aperture of the prototype must be unshaded during experiments. This precludes direct access to the electrical terminals of each miniature PV panel and necessitates extending wires through one end of the prototype. Therefore, fabrication considered extending the positive and negative terminals of each miniature PV panel for a total length of $600 \mathrm{~mm}$ without significantly increasing the electrical resistance of the setup. To select an appropriate electrical conductor, an experiment was undertaken to evaluate two wire options, i.e., low-weight tinned copper ribbon measuring $1.5 \mathrm{~mm}$ wide and $0.2 \mathrm{~mm}$ thick $\cong 0.3 \mathrm{~mm}^{2}$ in cross-sectional area and low resistance single core stranded copper wire of nominal cross-sectional area $2.5 \mathrm{~mm}^{2}$. The experiment consisted of placing one of the miniature PV panels under a solar simulator and measuring the incident irradiance using a Kipp \& Zonen-CM11 pyranometer (calibrated on $15^{\text {th }}$ June 2018 in accordance with ISO 9847, type IIc) connected to a digital multimeter (Mastech MAS830L) to measure voltage. Conversion of the voltage measurement of the pyranometer, $V_{\text {pyra }}$ (in millivolt) into the corresponding irradiance, $G$ (in $\mathrm{W} / \mathrm{m}^{2}$ ) at the mounting position utilised Eq.(2),

$$
G=V_{\text {pyra }} \times 1000 / \partial_{G}
$$


Two handheld multimeters and the an I-V tracer (Daystar DS1000) were then installed according to the circuit schematic in Fig. 6 and current and voltage outputs of the miniature PV panel were measured for measured solar radiation of $858 \pm 21 \mathrm{~W} / \mathrm{m}^{2}$ and $987 \pm$ $21 \mathrm{~W} / \mathrm{m}^{2}$ provided by the solar simulator at the mounting position. The uncertainty of $\pm 21 \mathrm{~W} / \mathrm{m}^{2}$ in the measured irradiance is due to the resolution of the voltage display (one decimal place) of digital multimeter. A resolution of $0.1 \mathrm{mV}$ of the digital multimeter means a rounding error of $\pm 0.05 \mathrm{mV}$, resulting in an uncertainty of $\pm 10.7 \mathrm{~W} / \mathrm{m}^{2}$ using Eq.(2) and an expanded uncertainty of $\pm 21 \mathrm{~W} / \mathrm{m}^{2}$ with a coverage factor of $k=2$ (UKAS, 2012).

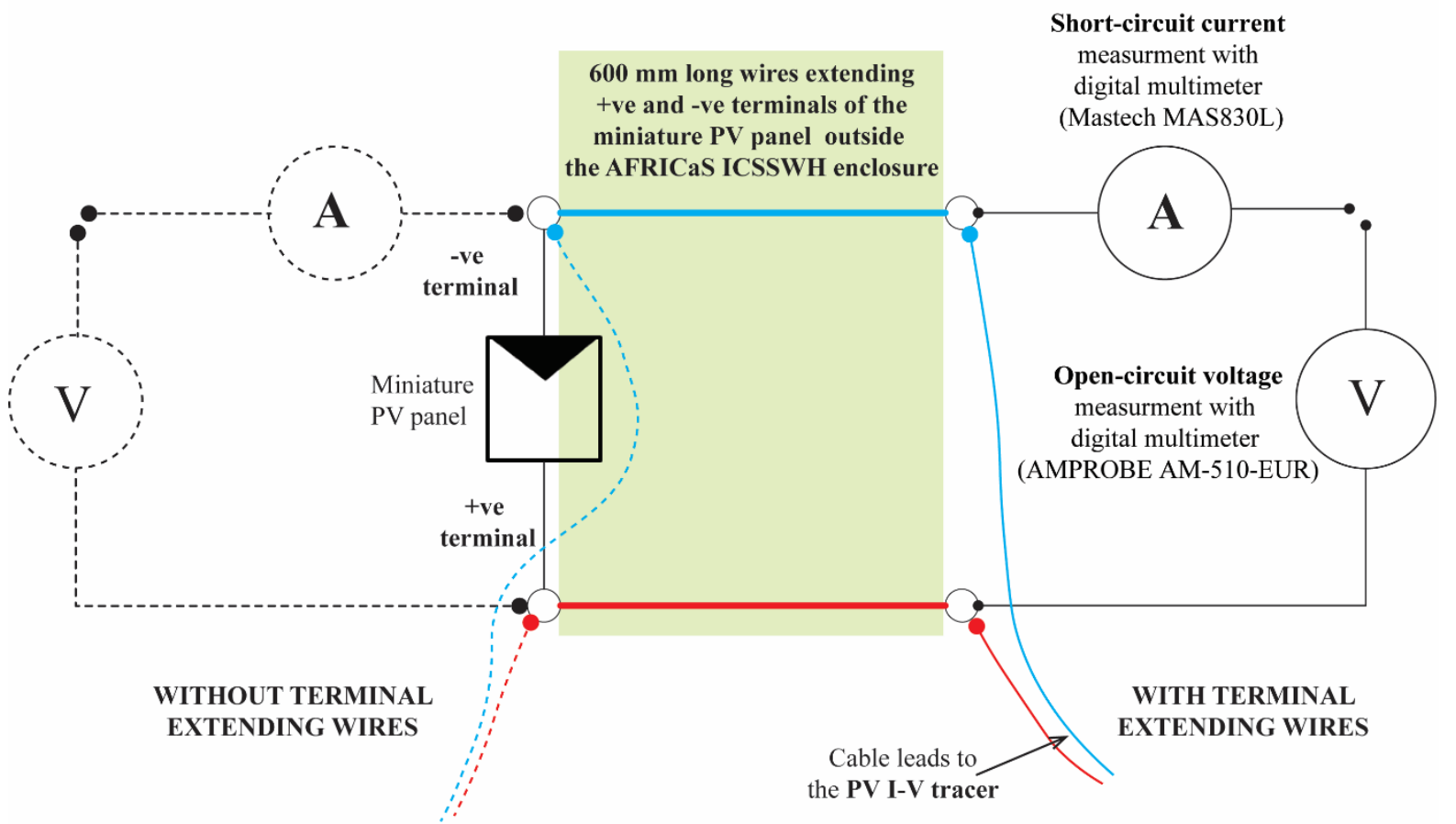

Fig. 6. Circuit schematic to evaluate suitable electrical conductors to extend the positive and negative terminals using one of the miniature PV panels, two handheld digital multimeters to measure current and voltage and an I-V tracer (Daystar DS1000).

The experiment measured voltage and current produced by one miniature PV panel mounted in position for three scenarios: (a) no terminal extending wires, (b) terminals extended with low-weight tinned copper ribbon (estimated weight $2.9 \mathrm{~g} / \mathrm{m}$ ) and (c) terminals extended with low resistance single core stranded copper wire (nominal weight $35 \mathrm{~g} / \mathrm{m}$ ). The setup utilised for testing the different experimental scenarios under the solar simulator is shown in the photograph of Fig. 7. As expected, low resistance single core stranded copper wire performed 
better than low-weight tinned copper ribbon but resulted in a heavy and rigid device. The thick low resistance single core stranded copper wire was difficult to handle and caused kinks at soldered joints, breaking terminal connections and damaging the soldered contacts at the PV cells during wire routing.

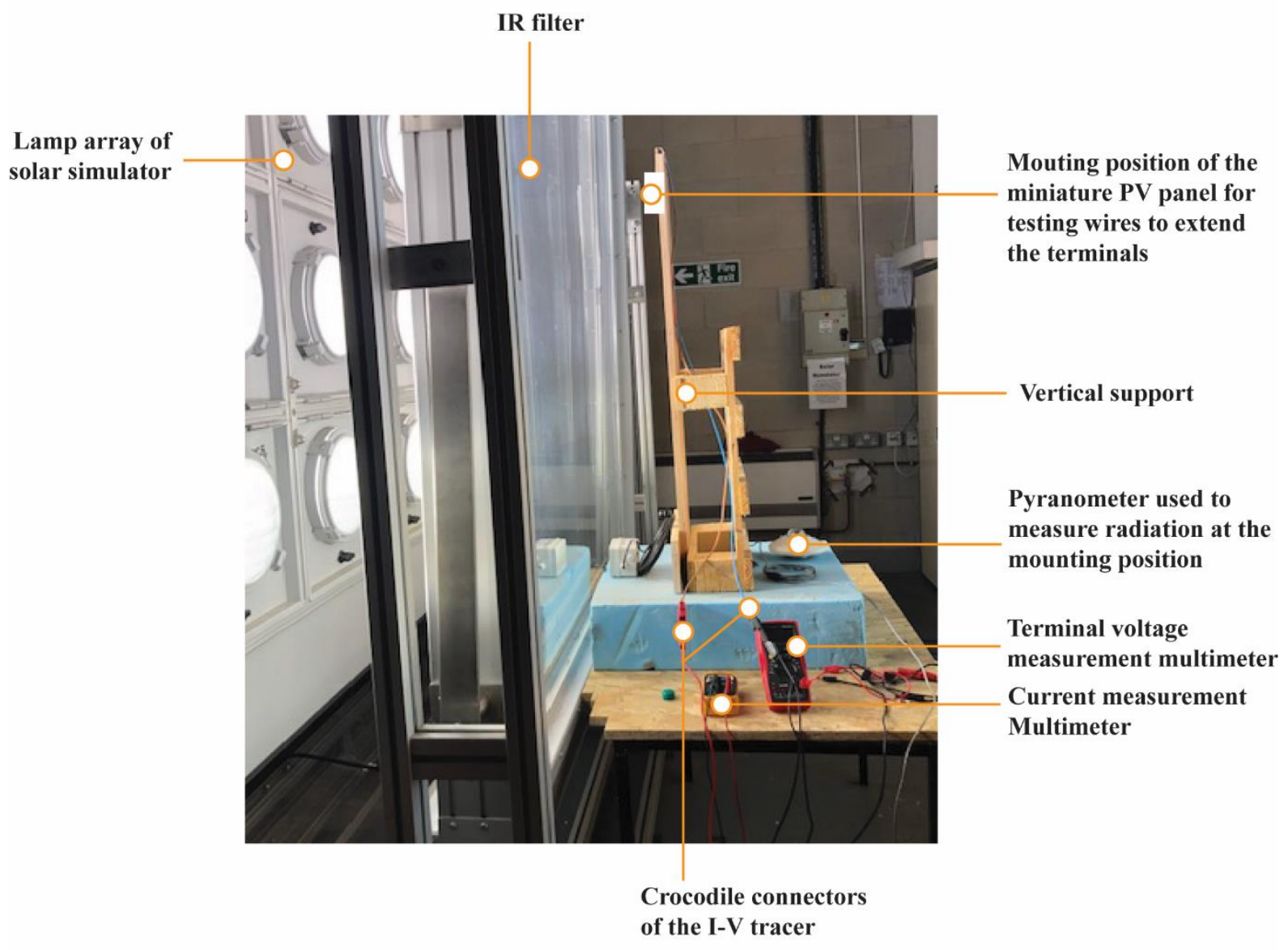

Fig. 7. Experimental testing of appropriate terminal extending wires using a single miniature PV panel

294 Consequently, low-weight tinned copper ribbon was selected as a favourable alternative to low resistance single core stranded copper wire for extending the terminals of each miniature PV panel. Low-weight conductors have a higher electrical resistance which could produce erroneous current measurements with a handheld digital multimeter at higher irradiance levels. However, a photovoltaic I-V curve tracer DS-1000 (Daystar, n.d.) is capable of presenting zero impedance at the extended terminals of miniature PV panels as opposed to a handheld digital multimeter which has internal impedance. The Daystar I-V tracer DS-1000 varies the impedance of its internal capacitive load from zero to infinity. This changes the operating point of the miniature PV panel from short-circuit current condition to open-circuit voltage condition to obtain an I-V curve. 
304 Fig. 8 depicts the fabricated device consisting of 12 discrete miniature PV panels and the 305 extension of the positive and negative terminals using low weight tinned copper ribbons. A 306 handheld digital multimeter confirmed functional operation of each parallel connection the 307 soldered PV cell strips as shown in Fig. 8a. The bare tinned copper ribbon wires were insulated 308 using heat shrink tubing (diameter $2.5 \mathrm{~mm}$ and shrinkage ratio 1:3) colour coded at the ends 309 (yellow for positive and black for negative) to prevent short-circuiting during wire routing as 310 shown in Fig. 8b. Fig. 8c shows the completed device consisting of 12 discrete miniature PV 311 panels with terminal extending wires and hooked on two flexible Velcro strands. Fig. 9 shows 312 the mounting of the completed device on the absorber of the prototype and the routing of 313 terminal extending wires for external access during experimental measurements. The wires 314 were indexed with numbers corresponding to the number positions of the discrete miniature 315 PV panels placed around the cylindrical absorber (see Fig. 4) to ensure a robust experiment. 
$\mathbf{a}$
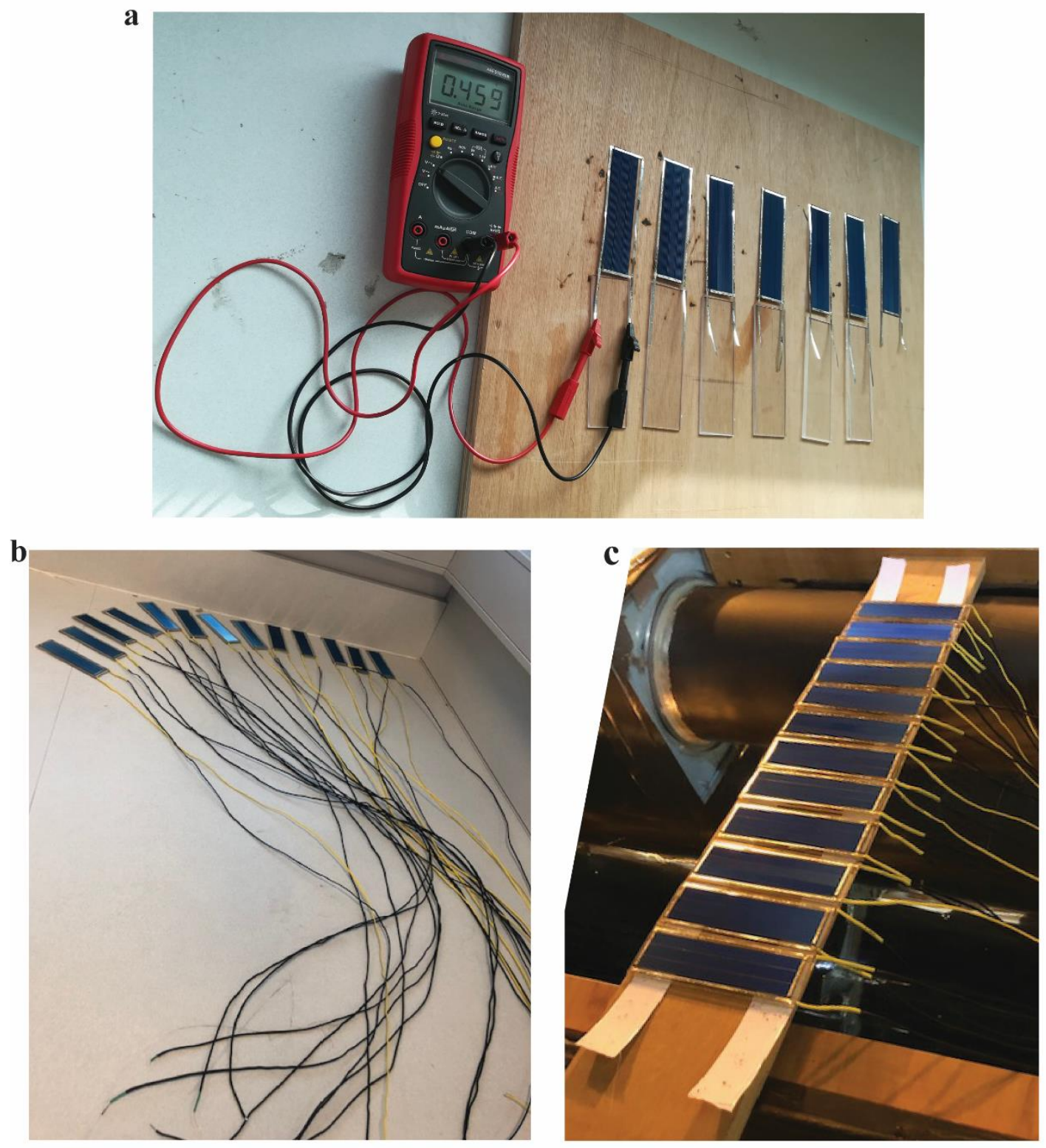

Fig. 8. The fabrication process from (a) soldering of PV cell strips with tinned copper ribbons 318 to create each miniature PV panel, (b) extending the positive and negative terminals for the 31912 miniature PV panels and an additional spare, (c) to the completed device of 12 miniature 320 PV panels on flexible Velcro tape strands pending mounting around the cylindrical absorber. 

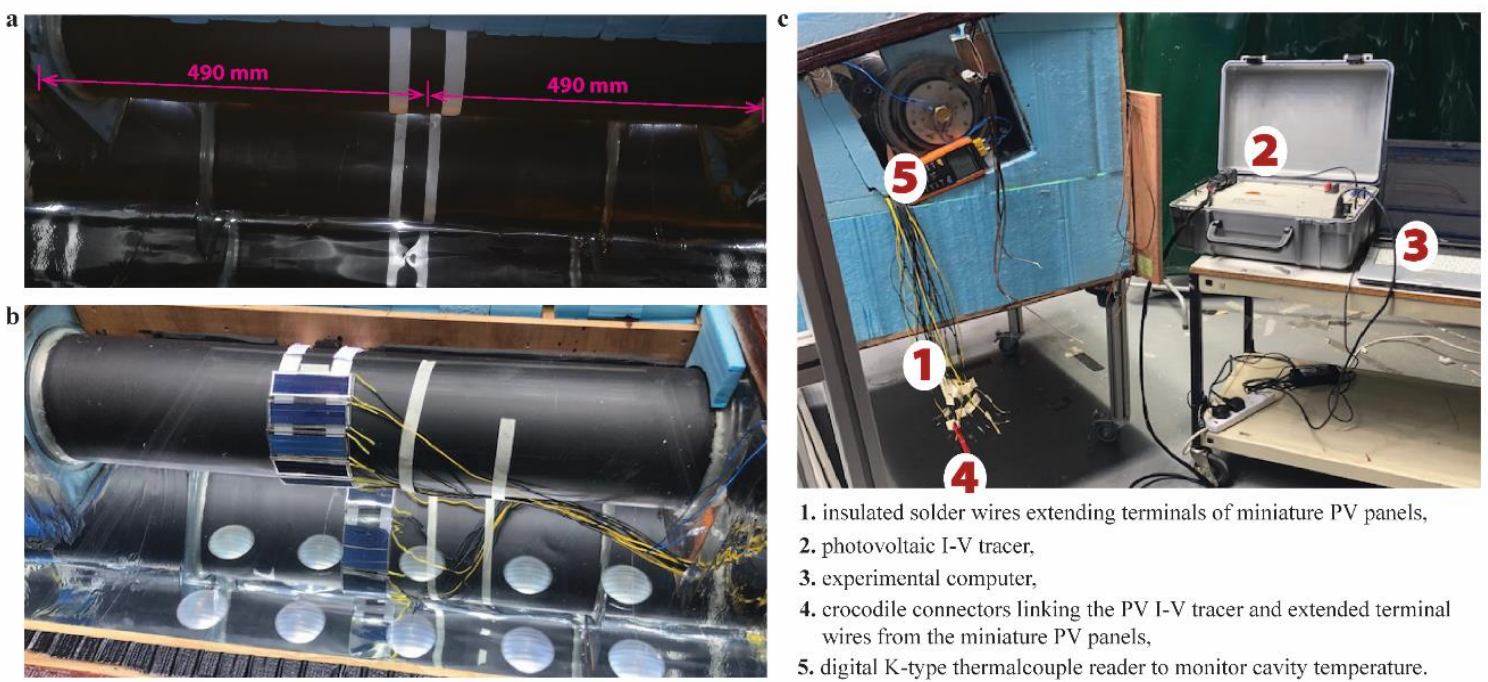

Fig. 9. Preparation of the experiment. (a) the wrapping of two Velcro strands (loop side) around the cylindrical absorber of the thermal diode ICSSWH mounted in the AFRICaS prototype, (b) the miniature PV panels hooked on the Velcro strand loops around the cylindrical absorber and (c) additional instrumentation and the complete experimental rig with wires extending electrical terminals of the 12 miniature PV panels hooked around the absorber for external access.

\subsubsection{The indoor and outdoor experimental procedure}

Indoor and outdoor experiments maintained the same set of instruments described in the foregoing sections including a pyranometer, handheld digital multimeter, PV I-V tracer and the fabricated device of 12 miniature PV panels. A thick piece of polystyrene foam insulation measuring $981 \mathrm{~mm}$ long $\times 523 \mathrm{~mm}$ wide and $50 \mathrm{~mm}$ thick was used to cover the aperture between measurements to avoid overheating of the PV cells in high solar radiation flux zones on the cylindrical receiver. A digital K-Type thermocouple reader (TENMA 72-7715) enabled continuous monitoring of the cavity temperature of the $\mathrm{CPC}$ reflector in the prototype enclosure. Solar radiation on the aperture at the various angles of incidence was measured as described in section 2.2.1 using a Kipp \& Zonen-CM11 pyranometer connected to a digital multimeter (Mastech MAS830L).

The indoor experiment involved placing the AFRICaS prototype under a solar simulator maintaining an appropriate distance (1.8m from lamps to AFRICaS aperture) to ensure the uniformity of artificial solar radiation and enable sufficient collimation. The solar simulator employs an array of 35 metal halide lamps and an earlier study (Zacharopoulos et al., 2009) established average uniformity and average collimation of $95 \%$ and $83 \%$, respectively with reference to the AM 1.5 spectrum. Arya et al (2018) present a concise description of the indoor 
solar simulator, its functional features and the spectral output. Fig. 10 shows the solar simulator, its light output spectrum compared to the AM 1.5 standard reference spectrum and the spectral responsivity (i.e., the ratio of the current produced by the PV cell to the radiative power incident on the PV cell in ampere per watt (A/W)) of a crystalline silicon PV cell. Tilting the solar simulator with respect to the aperture of the AFRICaS prototype achieved the required angles of incidence ranging from $-60^{\circ} \leq \theta_{i} \leq 60^{\circ}$ relative to the aperture plane normal. Angular tilt measurements of the solar simulator were measured using a digital inclinometer (FISCO Solatronic). For each angle of incidence, solar radiation intensity measurements were made on the aperture plane and two sets of readings from the miniature PV panel array were performed, both with and without glazing on the aperture. All experiments were undertaken with the Solar Simulator's IR filter in place to remove unrealistic infrared spectral components generated by the metal halide lamps.
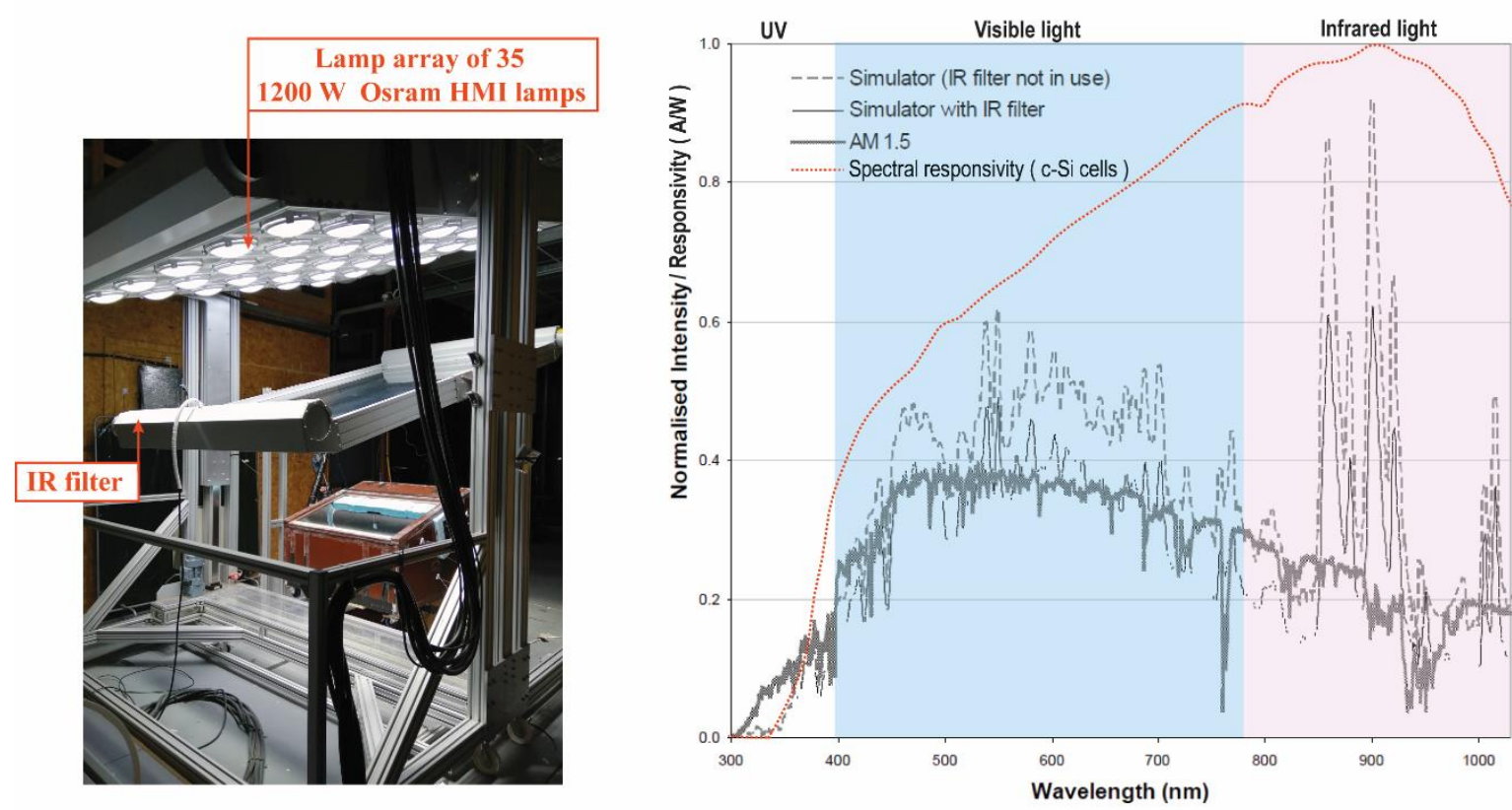

Fig. 10. Indoor solar simulator. Graph on the right shows the spectral output compared with AM 1.5 standard reference spectrum and the typical normalised spectral responsivity of crystalline silicon (Arya, 2014; Dirnberger et al., 2015; Theristis et al., 2018)

For outdoor experiments, the AFRICaS prototype was moved to the roof of the main laboratory building of Ulster University at Jordanstown campus, Northern Ireland, UK $\left(54^{\circ} 41^{\prime} 10^{\prime \prime} \mathrm{N}\right.$ $5^{\circ} 52^{\prime} 55^{\prime \prime} \mathrm{W}$ ) as shown in Fig. 11a. For each duration of 12 outdoor measurements (one for each miniature PV panel in place around the absorber arc), a custom-built device (Fig. 11b) was utilised to ensure that the solar vector remained in the meridian plane of the AFRICaS aperture. In addition, circles with radii corresponding to the shadow-length of a pin fixed normal to the 
surface of the custom-built device in Fig. 11b enabled tilt adjustments to set incidence angles from $-60^{\circ} \leq \theta_{i} \leq 60^{\circ}$ relative to the aperture plane normal. System alignment with the solar vector at the custom incidence angle-setting rig was checked at 4-minute intervals and adjusted to minimize alignment errors. A 4-minute interval corresponds to a one-degree change in the solar hour angle. All measurements were taken under clear sunny days while recording the total and diffuse solar radiation in the plane of the aperture. The diffuse part of solar radiation was measured using a custom-made opaque circular cardboard disc of $80 \mathrm{~mm}$ diameter (see Fig. 11c), which shaded the pyranometer thereby screening out the direct solar beam.

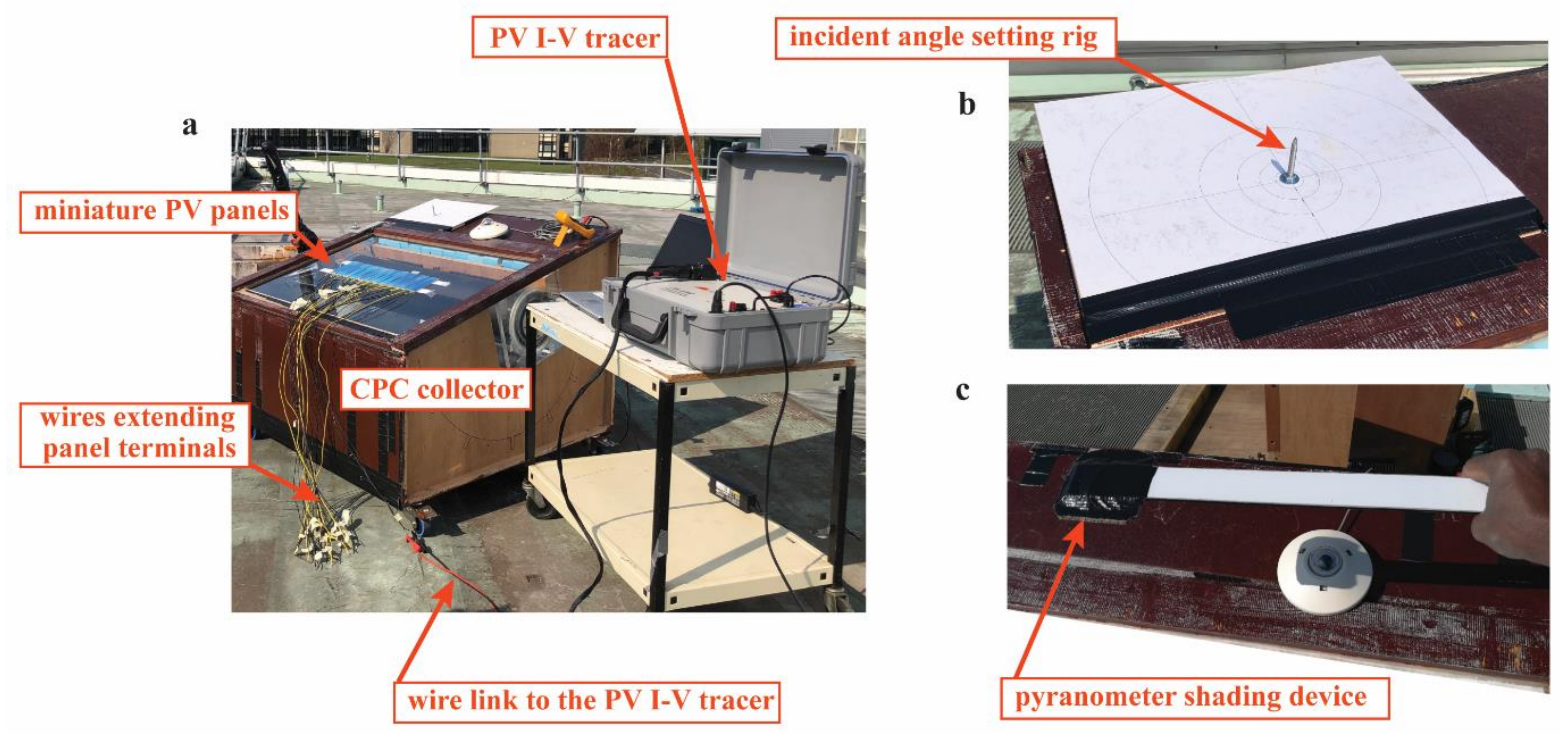

Fig. 11. Outdoor experimental setup. (a) AFRICaS prototype during outdoor measurement of the reference short circuit currents on the aperture including the (b) purpose made incident angle-setting rig and the (c) purpose made shading disc to facilitate the measurement of diffuse solar radiation.

Optical efficiency and the distribution of solar radiation flux around the cylindrical absorber are a function of the angle of incidence of solar radiation on the aperture. The short-circuit current produced by PV cells is proportional to the incident solar radiation intensity (Labouret and Villoz, 2010). Indoor and outdoor experiments validated this using one of the fabricated miniature PV panels to verify the relationship between short circuit current and solar radiation intensity as depicted in section 3.2, Fig. 14. The ratio of the total radiation measured on the absorber, $G_{\mathrm{abs}}\left(\right.$ in $\mathrm{W} / \mathrm{m}^{2}$ ) to the total radiation measured on the aperture, $G_{\text {ap }}\left(\mathrm{in} \mathrm{W} / \mathrm{m}^{2}\right.$ ) provides an estimate of the dimensionless local CR produced by the reflector according to Eq.(3),

$$
C R=G_{\mathrm{abs}} / G_{\mathrm{ap}}=I_{\mathrm{SC}, \mathrm{abs}} / I_{\mathrm{SC}, \mathrm{ap}}
$$


where, $I_{\mathrm{SC}, \text { abs }}$ is the short-circuit current measured with an individual miniature PV panels in one of the 12 positions around the receiver and $I_{\mathrm{SC} \text {,ap }}$ is the short-circuit current measured with an individual miniature PV panel placed on the aperture of the AFRICaS aperture.

Several tests were undertaken to determine reference responses of the PV panels and to verify their linearity in terms of the relationship between irradiance $\left(G_{\mathrm{ref}}\right)$ and short circuit current $\left(I_{\mathrm{SC}, \mathrm{ref}}\right)$. Due to differences in outdoor and indoor solar radiation conditions, reference conditions were established in separate indoor and outdoor experiments. Current-Voltage (IV) curves were obtained using a photovoltaic I-V curve tracer, DS-1000 (Daystar, n.d.), via a computer for accurate determination of the short circuit current produced by the individual miniature PV panels in their respective positions. Using reference values determined from initial measurements, Eq.(4) was used to obtain the short circuit current $\left(I_{\mathrm{SC}, \mathrm{ap}}\right)$ corresponding to the measured solar radiation on the aperture $\left(G_{\mathrm{ap}}\right)$ for a particular incidence angle.

$$
I_{\mathrm{SC}, \mathrm{ap}}=\left(I_{\mathrm{SC}, \mathrm{ref}} \times G_{\mathrm{ap}}\right) / G_{\mathrm{ref}}
$$

\subsubsection{Ray Tracing Model (RTM) and simulation}

Simulation of the solar radiation flux distribution on the absorber of the prototype employed a computer-based 2D RTM for several incidence angles ranging from $-60^{\circ} \leq \theta_{i} \leq 60^{\circ}$. The RTM has been progressively developed in-house by Centre for Sustainable Technologies (CST) at Ulster University and validated in previous studies (Smyth et al., 1999a; Zacharopoulos, 2001; Souliotis et al., 2011; Zacharopoulos et al., 2012). Computer-based ray tracing simulations employed 5,000 rays for each incidence angle. The model traces each ray entering the aperture of the reflector until it intercepts the absorber or until it exits through the aperture of the system after multiple reflections (Zacharopoulos et al., 2012). Table 1 shows optical properties of materials in the ray tracing simulation, corresponding to material properties in the fabricated AFRICaS prototype. The RTM assumes parallel incident rays in the meridian of the reflector, ignoring end reflection effects. Results from the ray tracing simulation were analysed to visualise calculated values of concentration ratio around the desired region of the absorber thereby enabling experimental validation in accordance with Fig. 4 in section 2.2 . 
Table 1

417 Materials, devices and associated parameters

\begin{tabular}{|c|c|c|c|}
\hline Material or device & Parameter & Unit & Value/dimensions \\
\hline \multirow{3}{*}{$\begin{array}{l}\text { Ordinary glass (aperture } \\
\text { glazing) }\end{array}$} & $\begin{array}{l}\text { Extinction coefficient } \\
\text { (Kreith and } \\
\text { Krumdieck, 2013) }\end{array}$ & $\mathrm{m}^{-1}$ & 19.69 \\
\hline & $\begin{array}{l}\text { Length } \mathrm{x} \text { Width } \mathrm{x} \\
\text { Thickness }\end{array}$ & $\mathrm{mm}$ & $1108 \times 700 \times 4$ \\
\hline & Refractive index & - & 1.526 \\
\hline \multirow[b]{2}{*}{$\begin{array}{l}\text { Reflector (MIRO-SUN@) } \\
\text { (Alanod-Solar, n.d.) }\end{array}$} & Specular reflectance & - & 0.87 \\
\hline & $\begin{array}{l}\text { Length } \mathrm{x} \text { Width } \mathrm{x} \\
\text { Thickness }\end{array}$ & $\mathrm{mm}$ & 1337 x 981 x 0.5 \\
\hline $\begin{array}{l}\text { Receiver/ outer } \\
\text { cylindrical vessel }\end{array}$ & Radius & $\mathrm{mm}$ & 0 \\
\hline Pyranometer & Spectral sensitivity & $\mu \mathrm{V} / \mathrm{W} \mathrm{m}^{2}$ & 4.66 \\
\hline PV I-V Tracer & Model number & - & Daystar DS1000 \\
\hline $\begin{array}{l}\text { BP Solar Saturn c-Si PV } \\
\text { cell strip }\end{array}$ & $\begin{array}{l}\text { Length } \mathrm{x} \text { Width } \mathrm{x} \\
\text { Thickness }\end{array}$ & $\mathrm{mm}$ & 0.4 \\
\hline Perspex substrate & $\begin{array}{l}\text { Length } \mathrm{x} \text { Width } \mathrm{x} \\
\text { Thickness }\end{array}$ & & $120 \times 39 \times 2.5$ \\
\hline $\begin{array}{l}\text { Heavy-duty sticky back } \\
\text { and reusable Velcro tape }\end{array}$ & Width x Thickness & & $25 \times 2$ \\
\hline \multirow{2}{*}{ Heat shrink tubing } & Diameter & $\mathrm{mm}$ & 2.5 \\
\hline & Shrinkage ratio & - & $1: 3$ \\
\hline \multirow{2}{*}{$\begin{array}{l}\text { Tinned copper ribbons } \\
\text { (Solder type: } 96.5 \% \text { Tin, } \\
\text { 3\% Silver and } 0.5 \\
\text { Copper) }\end{array}$} & Weight & $\mathrm{g} / \mathrm{m}$ & 2.9 \\
\hline & Cross-sectional area & $\mathrm{mm}^{2}$ & 0.3 \\
\hline \multirow{2}{*}{ Stranded copper wire } & Weight & $\mathrm{g} / \mathrm{m}$ & 35 \\
\hline & Cross-sectional area & $\mathrm{mm}^{2}$ & 2.5 \\
\hline \multirow{4}{*}{$\begin{array}{l}\text { Digital multimeter } \\
\text { (Mastech MAS830L) }\end{array}$} & DC current range & A & 10 \\
\hline & DC current resolution & $\mathrm{mA}$ & 10 \\
\hline & DC voltage range & $\mathrm{mV}$ & 200 \\
\hline & DC voltage resolution & $\mu \mathrm{V}$ & 100 \\
\hline \multirow{2}{*}{$\begin{array}{l}\text { Digital multimeter } \\
\text { (AMPROBE AM-510- } \\
\text { EUR) }\end{array}$} & DC voltage range & $\mathrm{V}$ & 4 \\
\hline & DC voltage resolution & $\mathrm{mV}$ & 1 \\
\hline \multirow{3}{*}{$\begin{array}{l}\text { Solar Simulator } \\
\text { (Zacharopoulos et al., } \\
\text { 2009) }\end{array}$} & $\begin{array}{l}\text { Number of metal } \\
\text { halide lamps }\end{array}$ & - & 35 \\
\hline & Lamp rows $\mathrm{x}$ columns & - & $7 \times 5$ \\
\hline & $\begin{array}{l}\text { Lamp housing (length } \\
\mathrm{x} \text { width } \mathrm{x} \text { depth) }\end{array}$ & $\mathrm{mm}$ & $\begin{array}{c}2750 \times 2020 \times \\
350\end{array}$ \\
\hline $\begin{array}{l}\text { EN17 digital } \\
\text { inclinometer, FISCO } \\
\text { Solatronic }\end{array}$ & $\begin{array}{l}\text { Accuracy } \\
\text { specifications }\end{array}$ & Degrees $\left(^{\circ}\right)$ & $\begin{array}{c} \pm 0.05^{\circ} \text { (for } 0^{\circ}, \\
\left.90^{\circ}\right), \pm 0.2 \text { (for } \\
\text { other angles } 1^{\circ} \text { to } \\
89^{\circ} \text { ) }\end{array}$ \\
\hline
\end{tabular}




\section{Results and discussion}

419

420

421

422

423

424

425

426

427

428

\subsection{Optical results from the ray tracing simulation}

Fig. 12 considers a practical range of incidence angles on the aperture to show results of the ray tracing simulation including optical efficiency and angular acceptance function of the asymmetric CPC profile. The angular acceptance function confirms that the inverted asymmetric CPC design provides a significant field of view with angular acceptance ranging from $93.5 \%$ to $99.1 \%$ for incidence angles ranging from $45^{\circ}$ to $-45^{\circ}$, respectively. The incidence angle of solar radiation is the angle between the perpendicular plane at the aperture of the collector and the incident ray as earlier depicted in Fig. 4. The optical efficiency increases from $64.6 \%$ at an incidence angle of $0^{\circ}$ and reaches $74.0 \%$ for incidence angles in the range $-40^{\circ} \leq \theta_{i} \leq-45^{\circ}$.

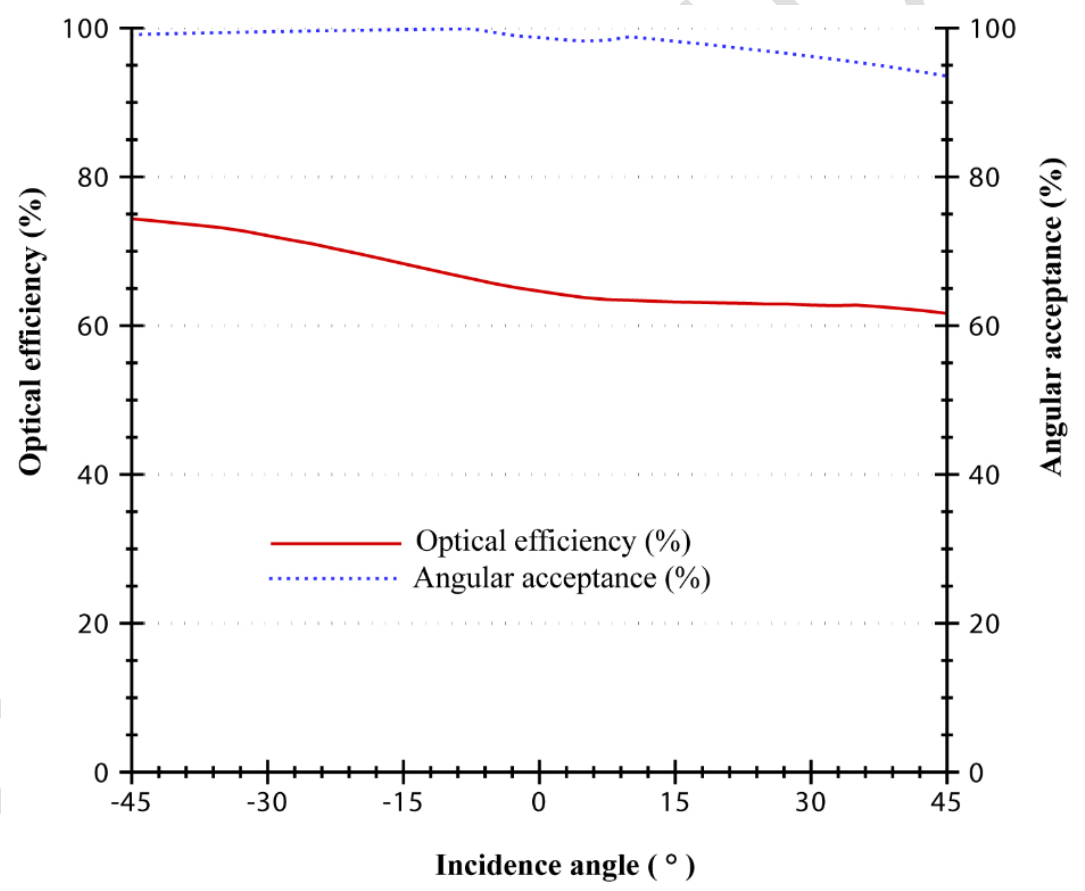

Fig. 12. Ray tracing model results showing optical efficiency and angular acceptance for the glazed asymmetric CPC as functions of the incidence angle.

Fig. 13 presents a summary of ray tracing simulation results of local concentration ratio around the illuminated circumference of the absorber for various angles of incidence ranging from $-60^{\circ} \leq \theta_{i} \leq 60^{\circ}$. It also highlights the concerned targeted area of the absorber (CDE) and the preferred focal point (D). It is clear from the results that the asymmetric CPC profile distributes solar radiation flux around the targeted absorber surface to target the base of the ICSSWH where the phase change heat transfer fluid is located. The ray tracing simulation indicates that 
438 the distribution of solar radiation flux is nonuniform - an inherent problem with non-imaging 439 reflectors. At an incidence angle of $0^{\circ}$, the targeted zone (D) of the absorber receives a local 440 CR reaching 1.3 suns but higher CRs up to 8.5 appear near the periphery of the targeted zone 441 (E). This necessitates suitable absorber material to reduce the effect of hot spots. Ustaoglu et 442 al (2016) found that copper and aluminium absorbers attain greater uniformity in temperature 443 distribution on the absorber due to better thermal conductivity compared to stainless steel 444 absorbers. Peaks of high local CR shift further away from the target zone (from E towards P) 445 and into the inverted hot air cavity for increasing negative incidence angles but move further 446 into the targeted zone (from E towards D) for increasing positive incidence angles. Installation 447 of the device in a real operating scenario should therefore take account of this preference for 448 positive incidence angles as opposed to negative ones in respect of the local seasonal variations 449 in solar altitude. 

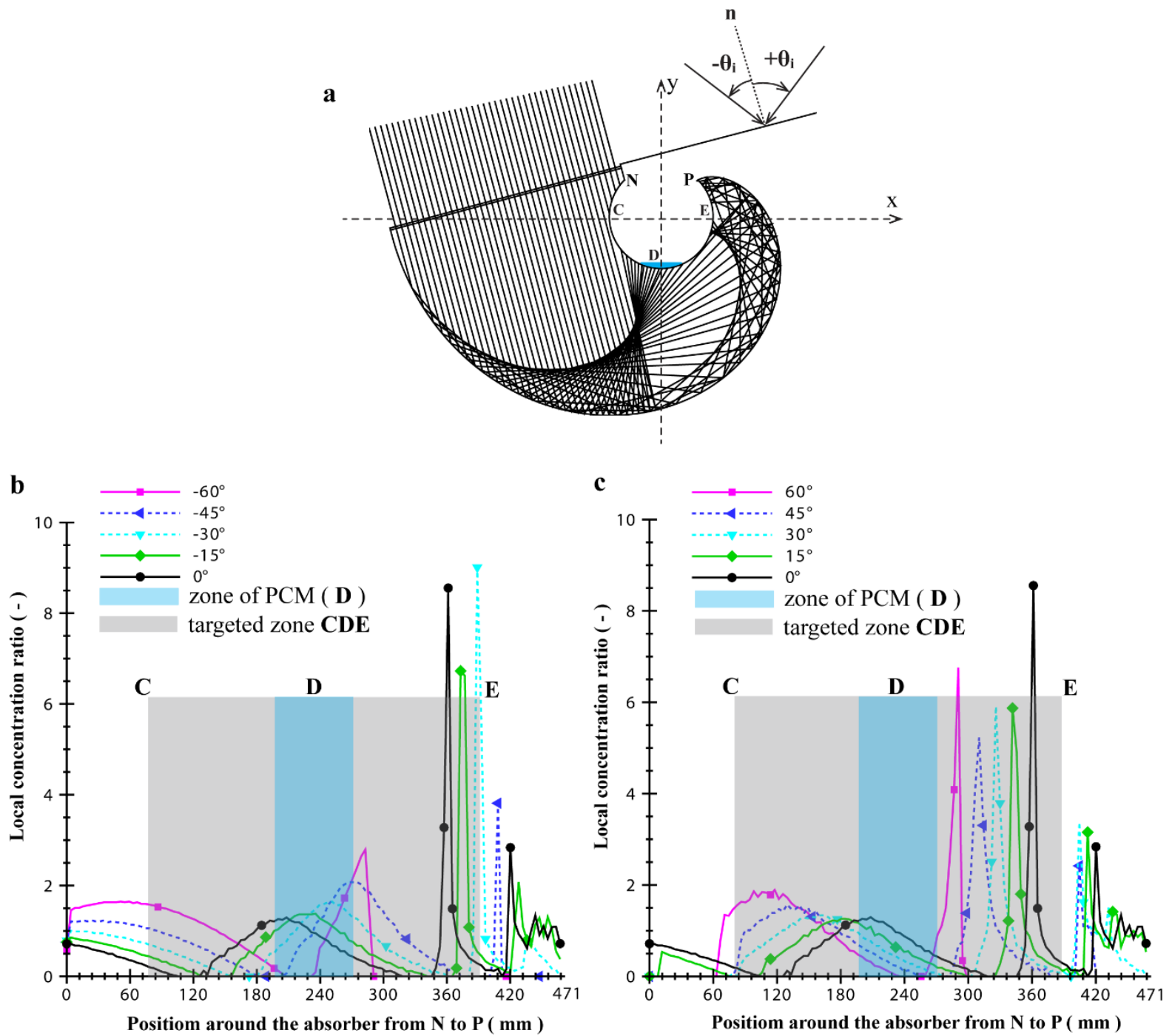

Fig. 13. Results of the ray tracing simulation for a glazed AFRICaS prototype showing (a) a ray tracing diagram for incidence angle $\theta_{\mathrm{i}}=0^{\circ}$ indicating the targeted zone (CDE) of the absorber and the preferred focal point (D); and solar radiation flux distribution plots for (b) negative incidence angles from $0^{\circ}$ to $-60^{\circ}$ and (c) positive incidence angles from $0^{\circ}$ to $60^{\circ}$.

\subsection{Correlation of ray tracing, indoor and outdoor experimental results}

The proportional relationship between short-circuit current at the terminals of crystalline silicon solar cells and the intensity of solar radiation has significant importance in the current experimental methodology. Fig. 14 shows correlations of short-circuit current and the measured solar radiation intensity in a series of outdoor and indoor experiments for one of the fabricated miniature PV panels. There is a discrepancy between the correlations of the outdoor and indoor cases owing to the spectral mismatch between sunlight and light from metal halide lamp arrays of the solar simulator as earlier shown in Fig. 10. Li et al (2015) has shown that the spectral composition of indoor light has an important influence on the output of PV cells optimised for natural light. Fortunately, dividing the short circuit currents produced by the same 
panels placed on the absorber and the aperture to calculate local concentration ratio using Eq.(3) eliminates the discrepancy.

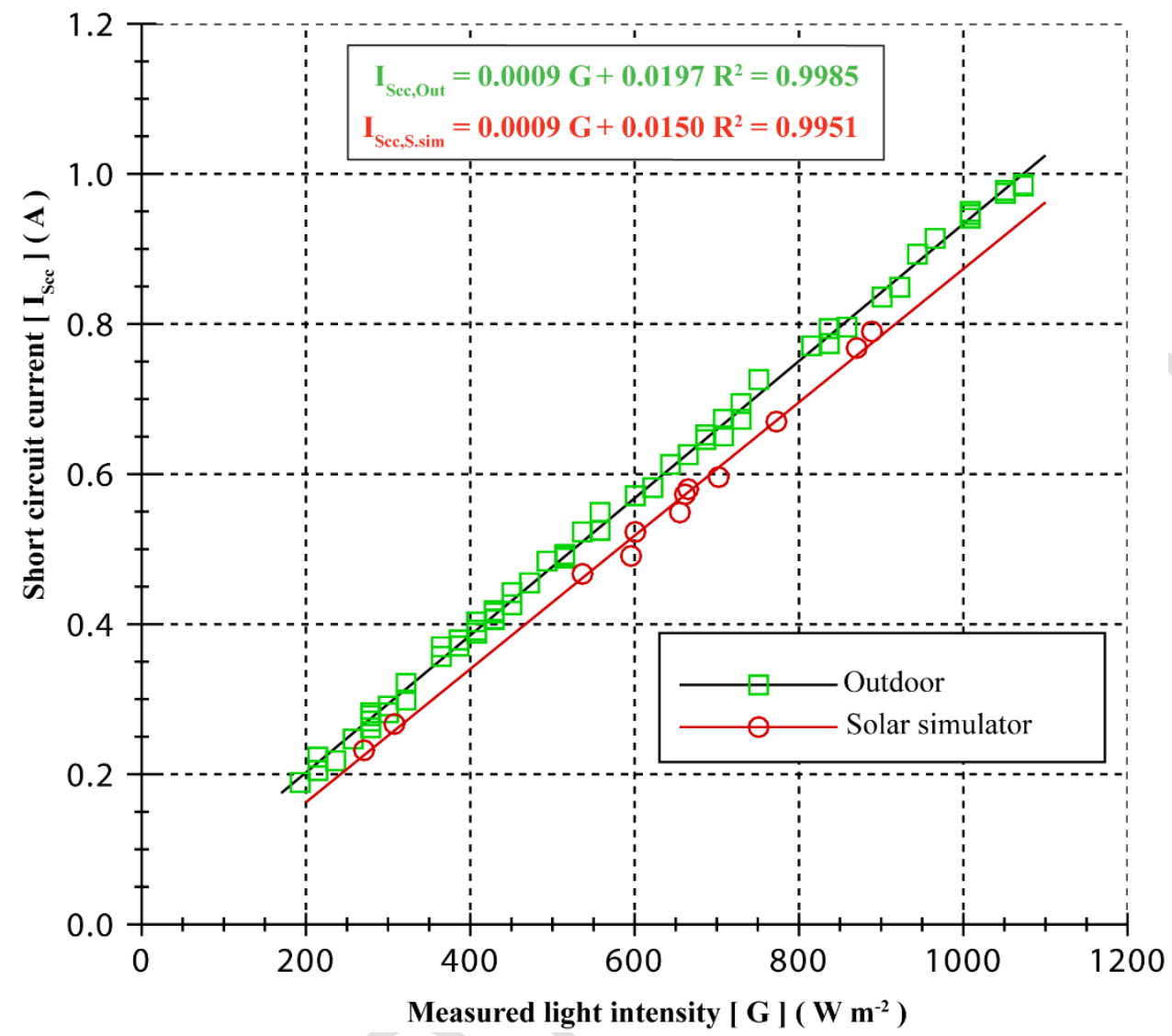

467

468 Fig. 14. Comparison of outdoor and solar simulator correlations between the measured light 469 intensity and short circuit current output for a single fabricated miniature PV panel.

470 Fig. 15 shows indoor and outdoor results of current-voltage curves of each miniature PV panel 471 for the $0^{\circ}$ incidence angle. During the indoor experiments with constant irradiance of $817 \pm$ $47221 \mathrm{~W} / \mathrm{m}^{2}$, the short-circuit current around the 12 positions (see Fig. 4 and Fig. 9) for the glazed 473 (Fig. 15a) AFRICaS prototype are up to $11 \%$ lower than in the unglazed (Fig. 15b) prototype. 474 This magnitude of losses is reasonable and occurs as solar radiation interacts with the glass 475 cover. Duffie and Beckman (2013) indicate that the reflection losses associated with a single 476 untreated glass pane reach $8 \%$ without considering reflection losses on reflector surface. 

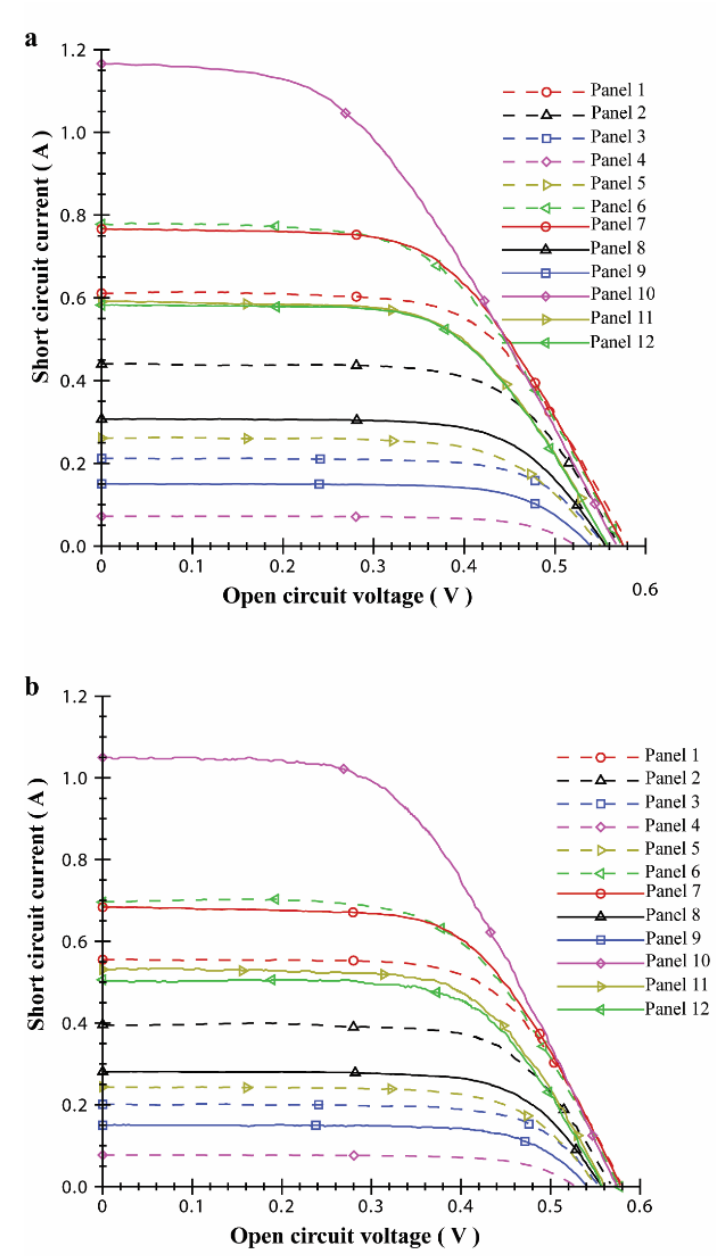

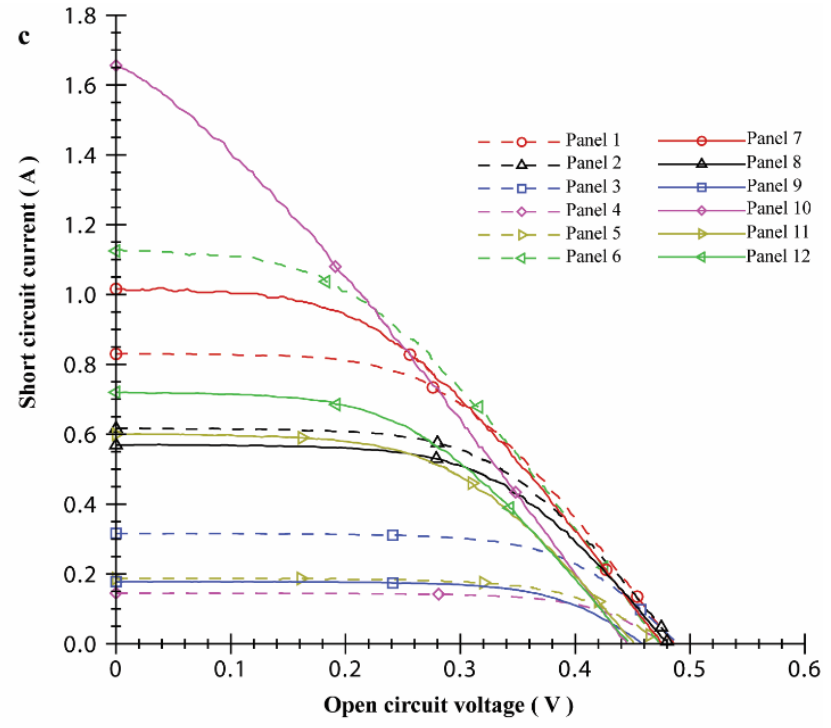

d

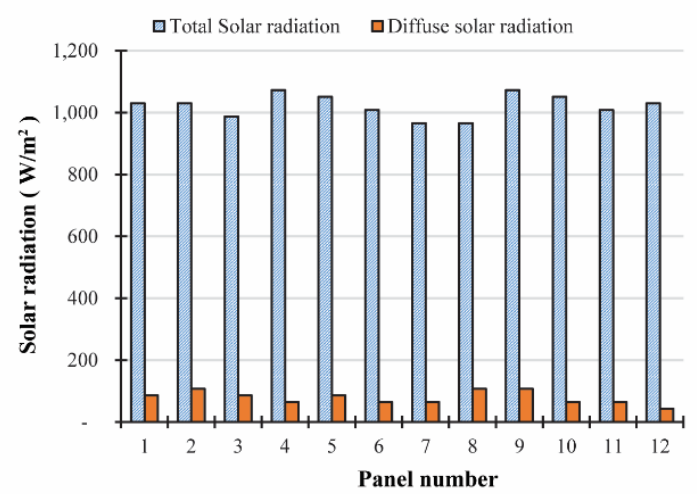

Fig. 15. Experimental results of I-V curves to derive short-circuit current values at an incidence angle of $\theta \mathrm{i}=0^{\circ}$ for (a) indoor testing of the unglazed AFRICaS prototype under the solar simulator at $817 \pm 21 \mathrm{~W} / \mathrm{m}^{2}$, (b) indoor testing of a glazed AFRICaS prototype under the solar simulator at $817 \pm 21 \mathrm{~W} / \mathrm{m}^{2}$; (c) outdoor testing of the glazed AFRICaS prototype for different corresponding (d) graphical values of total and diffuse solar irradiation measured on the glazed aperture.

For the outdoor case, Fig. 15c shows a significant increase in the short-circuit currents due to higher outdoor irradiances but also reflects the better response of BP Solar Saturn crystalline silicon PV cells to natural light. Also shown in Fig. 15d, are graphical measurements of total and diffuse solar radiation values recorded on the aperture during each I-V curve measurement with the miniature panels placed on the absorber surface. The total solar irradiance on the collector aperture during the clear sky period of the day ranged from $966 \pm 21 \mathrm{~W} / \mathrm{m}^{2}$ to $1073 \pm 21 \mathrm{~W} / \mathrm{m}^{2}$ whilst the measured diffuse component was as low as $100 \pm 21 \mathrm{~W} / \mathrm{m}^{2}$. At the incidence angle of $0^{\circ}$, panel 10 produces the highest short-circuit current in the outdoor experiment. The circumferential arc length covered by panel 10 in the ray tracing simulation ranges from $357 \mathrm{~mm}$ to $392 \mathrm{~mm}$ around the absorber (see Fig. 13) and is the region where ray 
tracing predicts a peak local concentration ratio reaching 8.5 suns for the incidence angle of $0^{\circ}$. This outdoor experimental result is also consistent with the indoor experimental result for the glazed and unglazed prototype and validates the result of the ray tracing simulation.

There is a considerable decline in the open circuit voltage produced by all miniature PV panels during the outdoor experiment compared to the open circuit voltage produced during the indoor experiments with unglazed (Fig. 15a) and a glazed (Fig. 15b) prototype. This arises from an increase in PV cell temperature (Joy et al., 2016). Notably so, the decrease in open circuit voltage during the outdoor experiment is greater for panel 10,11 and 12 which are located near the hot air trap and hence are likely to be subjected to a higher local ambient temperature. Additionally, the miniature PV panels were close to the black painted absorber, which would become warmer overtime such that the rise in PV cell temperature due to internal heat generation under higher solar irradiance may be less important. The temperature of PV cells has been found to have a modest impact on the short circuit current (Tian et al., 2012; Yadav et al., 2013). Since the present research utilises short circuit current measurements, the decline in open circuit voltage is of insignificant importance.

Fig. 16 compares the detailed experimental (outdoor and indoor) results of Fig. 15 and ray tracing simulation results of Fig. 13 for the incidence angle of $0^{\circ}$. Indoor experimental work and ray tracing simulations considered two scenarios of a glazed and unglazed prototype whilst outdoor experiments considered a glazed prototype only. There is significant consistency between the experimental results and the ray tracing simulation. The local CR defines the distribution of the solar radiation flux around the absorber surface. Each experimental measurement corresponds to the location of each miniature PV panel. Slight mismatches between ray tracing simulation predictions and measured results may be indicative of minor fabrication errors in certain sections of the asymmetric CPC profile or may be related to the fact that the ray tracing simulation is two dimensional and ignores end reflection effects that may be significant in the experimental prototype. 


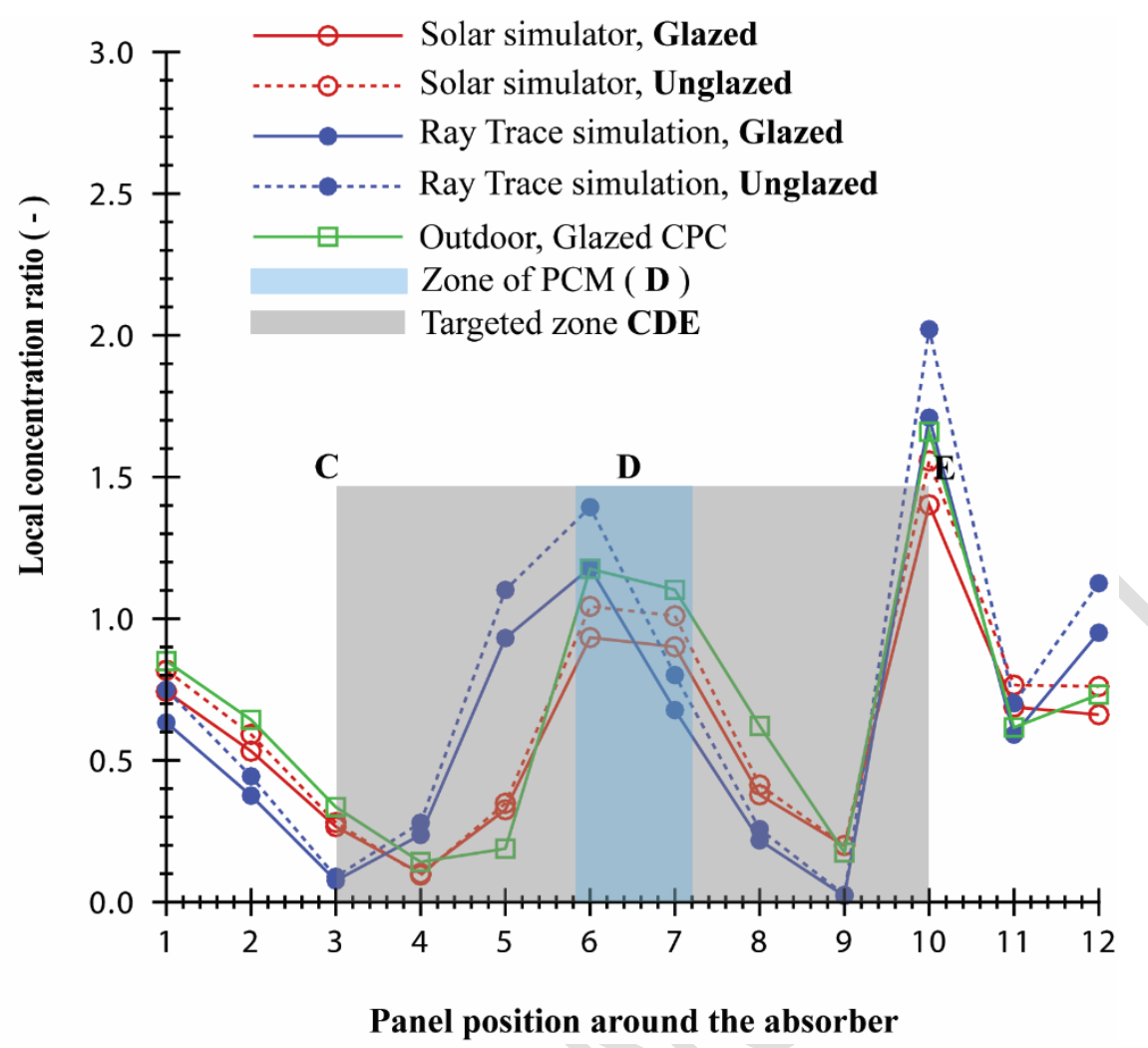

Fig. 16. Prediction of local CR by the ray tracing simulation and comparison with experimental results (indoor and outdoor) for an incidence angle of $\theta \mathrm{i}=0^{\circ}$. Also shown are the targeted zone $\mathrm{CDE}$ and preferred focal point $\mathrm{D}$ on the absorber circumference.

524 Fig. A. 1 and Fig. A. 2 in the Annex provide complete summaries of local CR results from the ray tracing simulation, the indoor and the outdoor experiments for other incidence angles. A closer look indicates that a range of incidence angles $-30^{\circ} \leq \theta_{i} \leq 30^{\circ}$ produces a $\mathrm{CR}$ greater than 1-sun in the absorber region interfacing the PCM, i.e., panels 5, 6, 7 and 8. This is an important finding for technical deployment of horizontally operating thermal diode ICSSWHs with an asymmetric CPC reflector in equatorial latitudes. The asymmetric inverted CPC reflector enables illumination of the bottom part of the absorber vessel and improvement of the thermal diode is probable but remains to be proven beyond doubt in future experimental work.

Fig. 17 summarises the experimental and simulated optical efficiencies of the glazed (Fig. 17a) and unglazed (Fig. 17b) cases of the asymmetric CPC reflector in the AFRICaS prototype as a function of incidence angle. There is close similarity in optical efficiency results predicted by the RTM and those derived from the indoor solar simulator and outdoor experiments for the glazed case, but a pronounced difference between the RTM and indoor solar simulator results for the unglazed case. As expected, glazing affects the optical efficiency. 
a

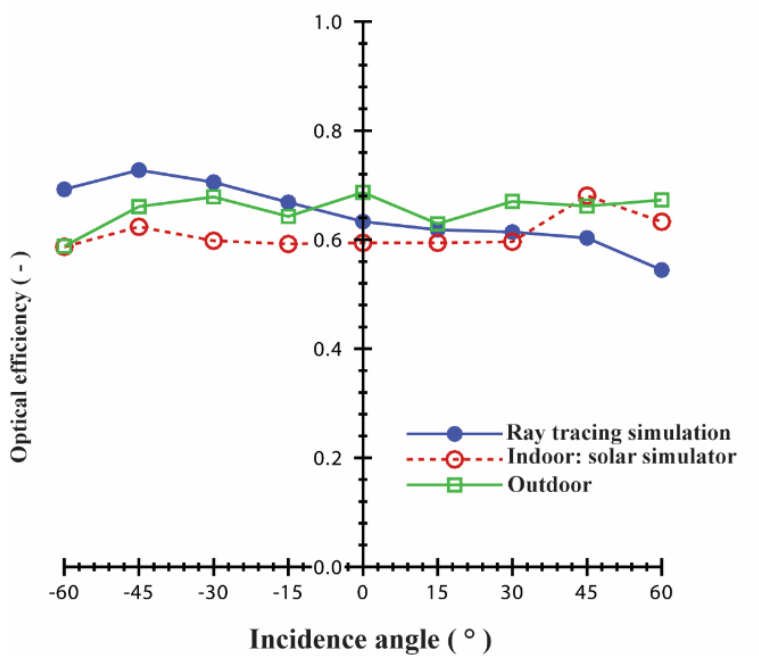

b

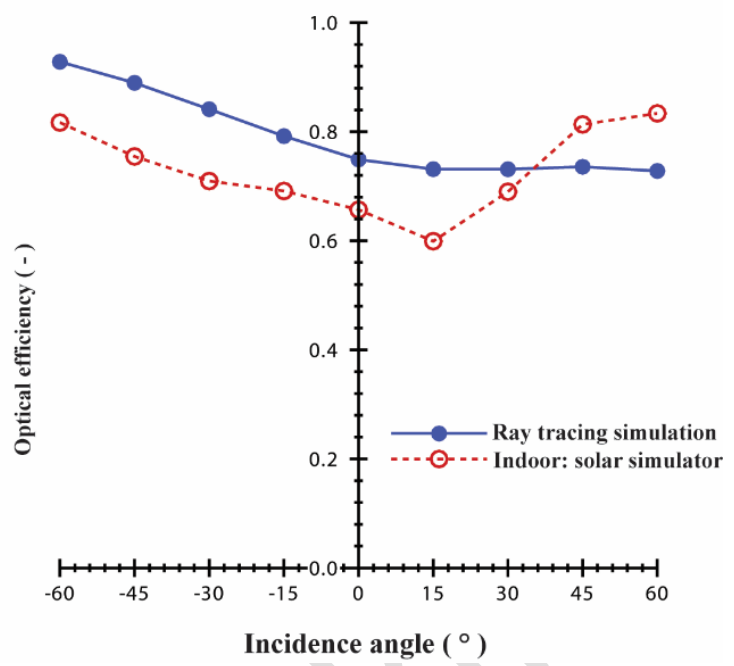

Fig. 17. Variation of optical efficiency of the AFRICaS prototype as a function of incidence 540 angles: (a) indoor, outdoor and ray tracing simulation for a glazed subsystem, (b) indoor and 541 ray tracing simulation for unglazed subsystem.

542 Table 2 summaries percentage differences between the modelled and experimentally realised 543 optical efficiencies for the AFRICaS prototype and compares these with results from 544 Zacharopoulos et al (2012) who investigated the performance of a different type of non545 imaging reflector using similar techniques. There was no outdoor testing of the unglazed 546 AFRICaS prototype in the present work whilst outdoor and indoor testing by Zacharopoulos et 547 al (2012) considered an unglazed device only. The main observations are: a) Indoor tests give 548 consistently lower optical efficiencies than the ray tracing simulation and also generally give 549 lower optical efficiencies than outdoor tests probably due to poor collimation, b) Ray tracing 550 simulations give optical efficiencies which, on average, are similar to those achieved in practice 551 outdoors, although some significant differences between predictions and measurements occur 552 at specific angles (presumably owing to inaccuracies in the reflector construction, PV cell 553 placement, solar vector alignment and other experimental limitations). 
Table 2

555 Comparison between studies of percentage differences in predicted results of optical efficiency in experiments using PV cells (indoor/outdoor)

556 and in the ray tracing simulation considering glazed and unglazed prototypes.

\begin{tabular}{|c|c|c|c|c|c|c|c|}
\hline \multirow{2}{*}{ Research work } & \multirow{2}{*}{$\begin{array}{l}\text { Incidence } \\
\text { angle }\left(^{\circ}\right)\end{array}$} & \multicolumn{2}{|c|}{ Outdoor vs indoor $(\%)$} & \multicolumn{2}{|c|}{ Outdoor vs ray tracing $(\%$} & \multicolumn{2}{|c|}{ Indoor vs ray tracing $(\%)$} \\
\hline & & Unglazed & Glazed & Unglazed & Glazed & Unglazed & Glazed \\
\hline \multirow{5}{*}{ This work } & -30 & - & 11.8 & - & -4.0 & -18.6 & -18.0 \\
\hline & -15 & - & 7.9 & - & -4.0 & -14.5 & -12.9 \\
\hline & 0 & - & 13.5 & - & 7.8 & -14.0 & -6.6 \\
\hline & 15 & - & 5.6 & & 1.7 & -22.1 & -4.0 \\
\hline & 30 & - & 11.0 & & 8.4 & -6.0 & -3.0 \\
\hline \multirow{5}{*}{$\begin{array}{l}\text { (Zacharopoulos et al., } \\
\text { 2012) }\end{array}$} & -30 & 2.2 & - & -3.2 & - & -5.5 & - \\
\hline & -15 & 3.0 & - & -1.7 & - & -4.8 & - \\
\hline & 0 & 1.7 & & -3.8 & - & -5.6 & - \\
\hline & 15 & 3.0 & & -1.7 & - & -4.9 & - \\
\hline & 30 & -2.2 & & -11.8 & - & -9.4 & - \\
\hline
\end{tabular}




\subsection{Investigation of accuracy in reflector realisation}

559 The ray tracing simulation generated results by utilising Eq.(1) to construct a perfect reflector

560

561

562

563

564

565

566

567

568

569

570

571

572

573

574

575

576

577 curve of Fig. 3b. The artisanal fabrication process realised the inverted involute curve by providing nine wooden supporting ribs to establish a support base for curving the reflector material. There are intrinsic inaccuracies in the reflector construction and extrinsic inaccuracies in performing the experiment such as placement of PV cells, incidence angle setting, solar vector alignment and other experimental limitations. While the degree of extrinsic inaccuracy in the experiment may be minimised by adequate experimental design, intrinsic inaccuracy in the reflector construction are irremediable from experimental results. To investigate the impact of inaccuracy due to residual fabrication errors, WebPlotDigitizer (Rohatgi, 2019) was used to generate a set of 108 random coordinates along the ideal reflector profile to mimic the artisanal fabrication process. Fig. 18 shows the distribution of the random points generated by the software along the ideal profile and indicates the placement of reflector wooden supporting ribs in the designed AFRICaS prototype.

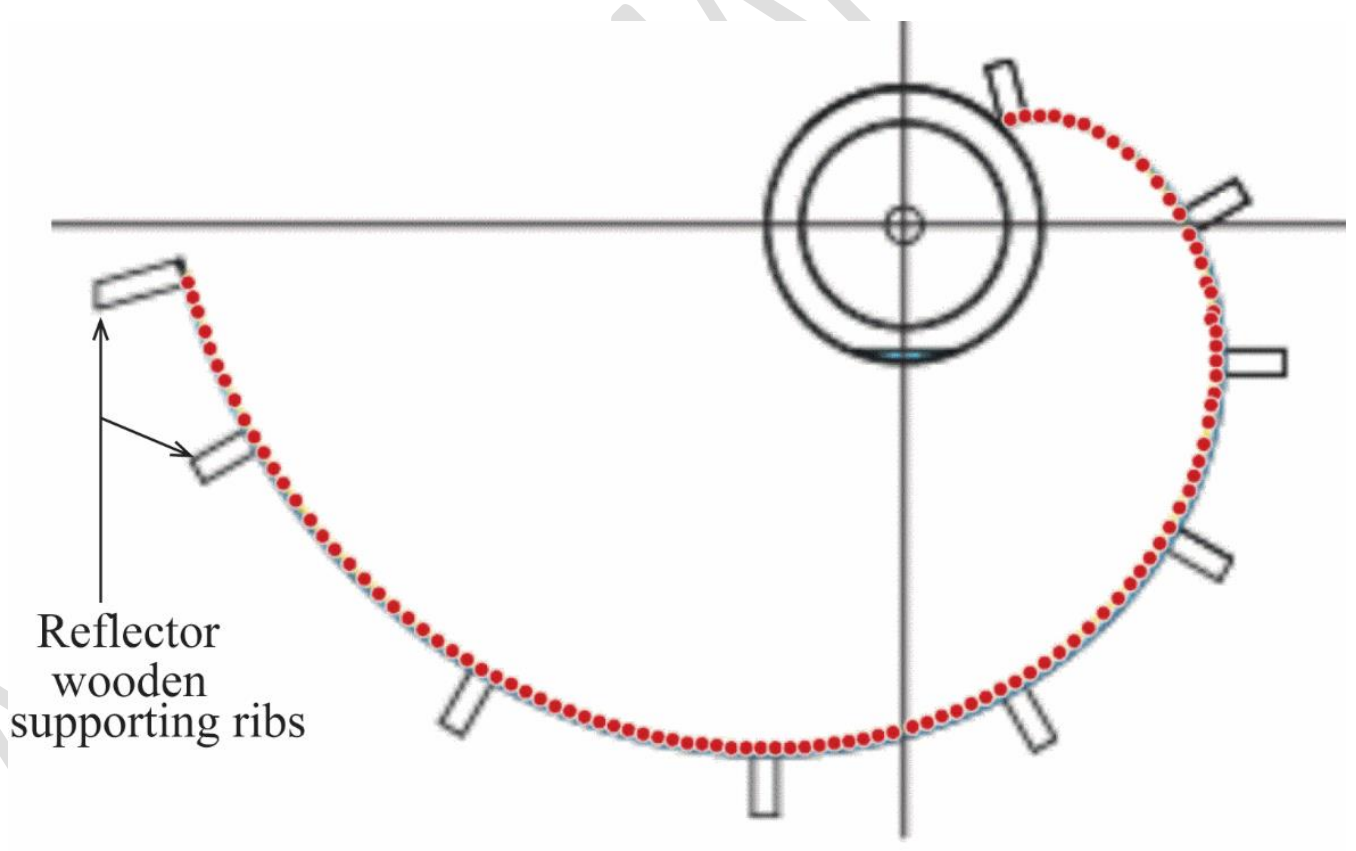

Fig. 18. Generation of a random imperfect reflector profile using WebPlotDigitizer (Rohatgi, 2019) as an approximation of the artisanal fabrication process.

The ray tracing diagrams for the $0^{\circ}$ angle of incidence of the glazed AFRICaS prototype design are presented in Fig. 19a for the perfect reflector profile and in Fig. 19b for the randomly generated imperfect reflector profile. Fig. 19c presents a graphical comparison of local CR of 
the imperfect reflector and the perfect reflector for the $0^{\circ}$ incidence angle. A distortion in the reflected rays is evident on the ray tracing diagrams. A mismatch between the predicted local $\mathrm{CR}$ of the randomly generated reflector profile and the perfect reflector profile in Fig. 19c is of a similar pattern to the results in Fig. 16 except that it occurs at different locations of the absorber. The randomly generated reflector profile produces a similar effect as the actual reflector realised by the artisanal fabrication process. Thus, the degree of intrinsic inaccuracy in the presented experimental results of the actual fabricated reflector may be of greater importance than the degree of extrinsic inaccuracy of performing the experiment.
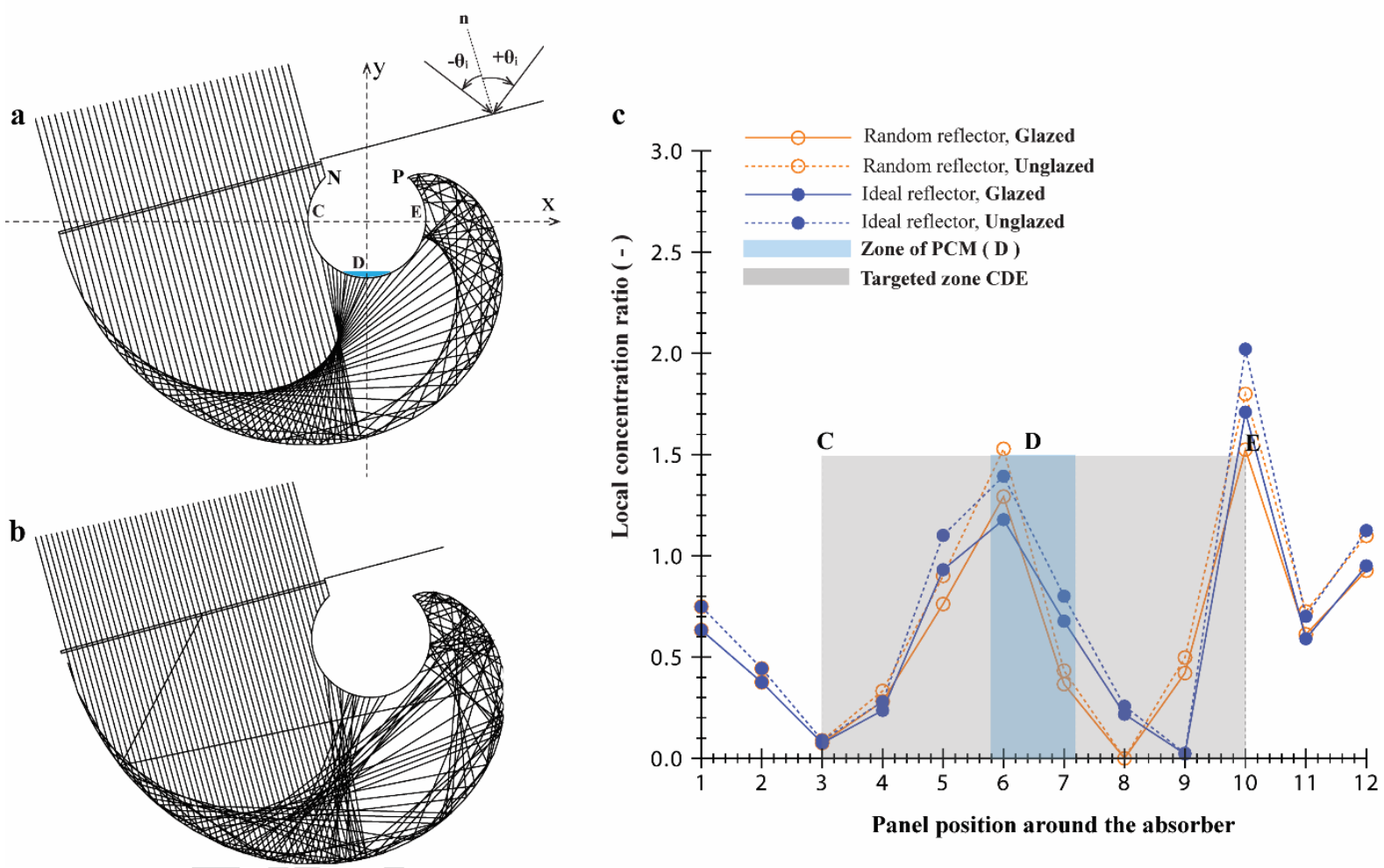

Fig. 19. Results comparison at $0^{\circ}$ incidence angle for a glazed AFRICaS prototype with ray tracing diagram of the (a) perfect reflector and the (b) imperfect reflector generated using WebPlotDigitizer (Rohatgi, 2019) and their (c) graphical comparison ray tracing results.

\section{Conclusions and future work}

This study develops a new experimental device to determine the distribution of solar radiation flux produced by an asymmetric CPC reflector around the absorber of a cylindrical thermal diode Integrated Storage Solar Water Heater (ICSSWH) using photovoltaic (PV) cells. It introduces the Asymmetric Formed Reflector with Integrated Collector and Storage (AFRICaS) system that achieves increased potential of solar radiation collection and corresponding heat flux distribution around a targeted section of the absorber with the aim of improving forward mode PCM heat transfer fluid evaporation rates. The study employs the 
new device in indoor and outdoor experiments to quantify solar radiation flux distribution on a cylindrical absorber and to determine concentration ratios (CRs) and optical efficiencies for the purpose of validating a computer-based ray tracing model (RTM) developed at Centre for Sustainable Technologies (CST) at Ulster University. The experimental method demonstrates that beneficial CRs are attainable in the targeted section of the absorber for improved solar energy collection potential. CR reaches 1.4 suns at the receiver section interfacing the PCM for incidence angles $-30^{\circ} \leq \theta_{i} \leq 30^{\circ}$. This range of incidence angles is useful for installations in equatorial latitudes. There is significant agreement between results from the ray tracing simulation and experiments. Future work should examine the current methodology in nonimaging reflectors with higher CRs and explore automatic rendering of multiple I-V curves and rapid extraction of short-circuit currents. Additionally, experimental and analytical work should explore the performance improvement of the thermal diode due to providing sunlight in the targeted section of the absorber and the corresponding thermal collection improvement of the system. Finally, the RTM lacks diffuse solar radiation modelling and it would be of interest to adapt the model algorithms to improve predictions for climates where hazy and cloudy conditions are prevalent.

\section{Acknowledgements}

This research was financially supported through an International Studentship provided by the Department for Education (DfE), Northern Ireland, UK. The work also benefitted from funding support from SolaForm Ltd and was undertaken in tandem with the SolaFin2Go project funded by the Engineering and Physical Sciences Research Council (EP/R035954/1) and Innovate UK Energy Catalyst Round 5 (IUK/133219). The author thanks Busitema University for the study leave and Mr. Edoardo Cao for assisting with terminal soldering of the PV cells.

\section{Declaration of interest}

\section{None.}


Incidence angle, $\theta_{\mathrm{i}}=-15^{\circ}$
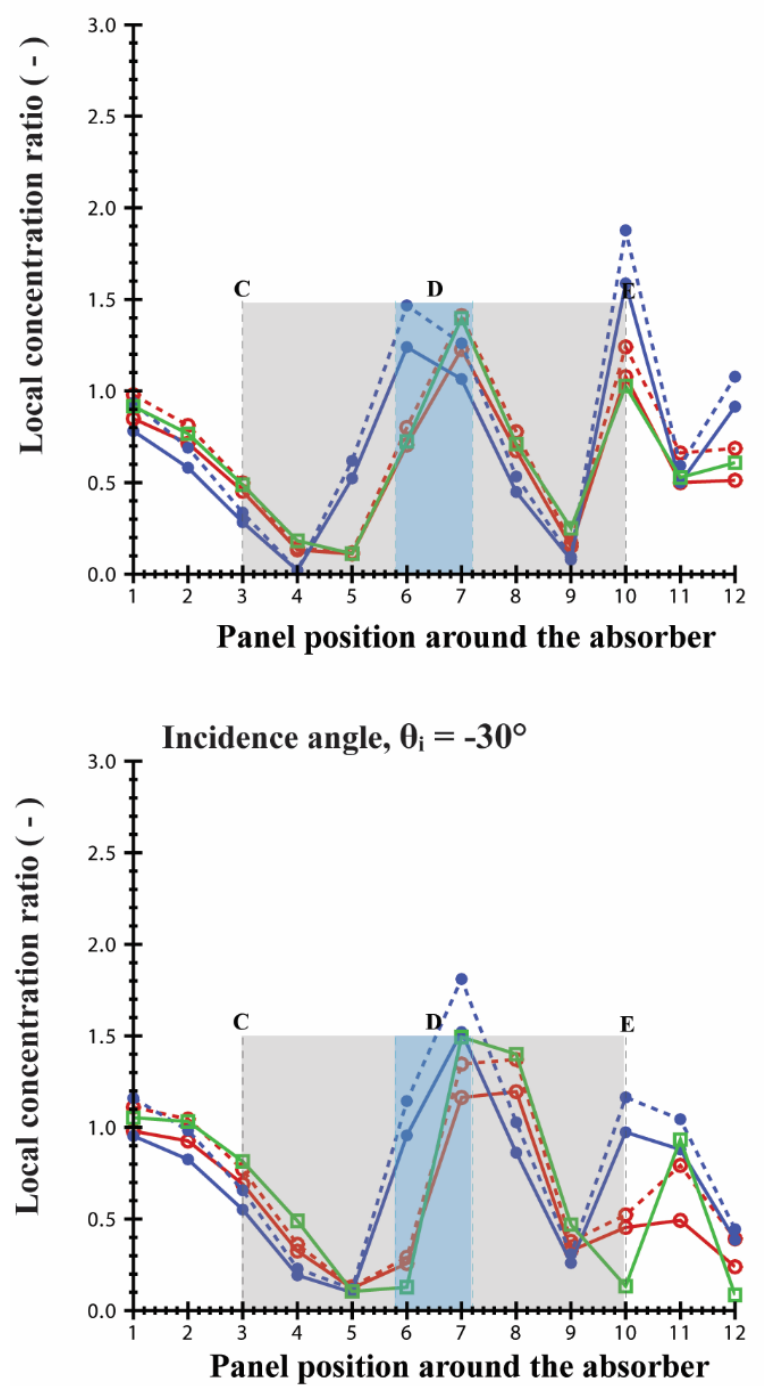

Incidence angle, $\theta_{\mathrm{i}}=15^{\circ}$
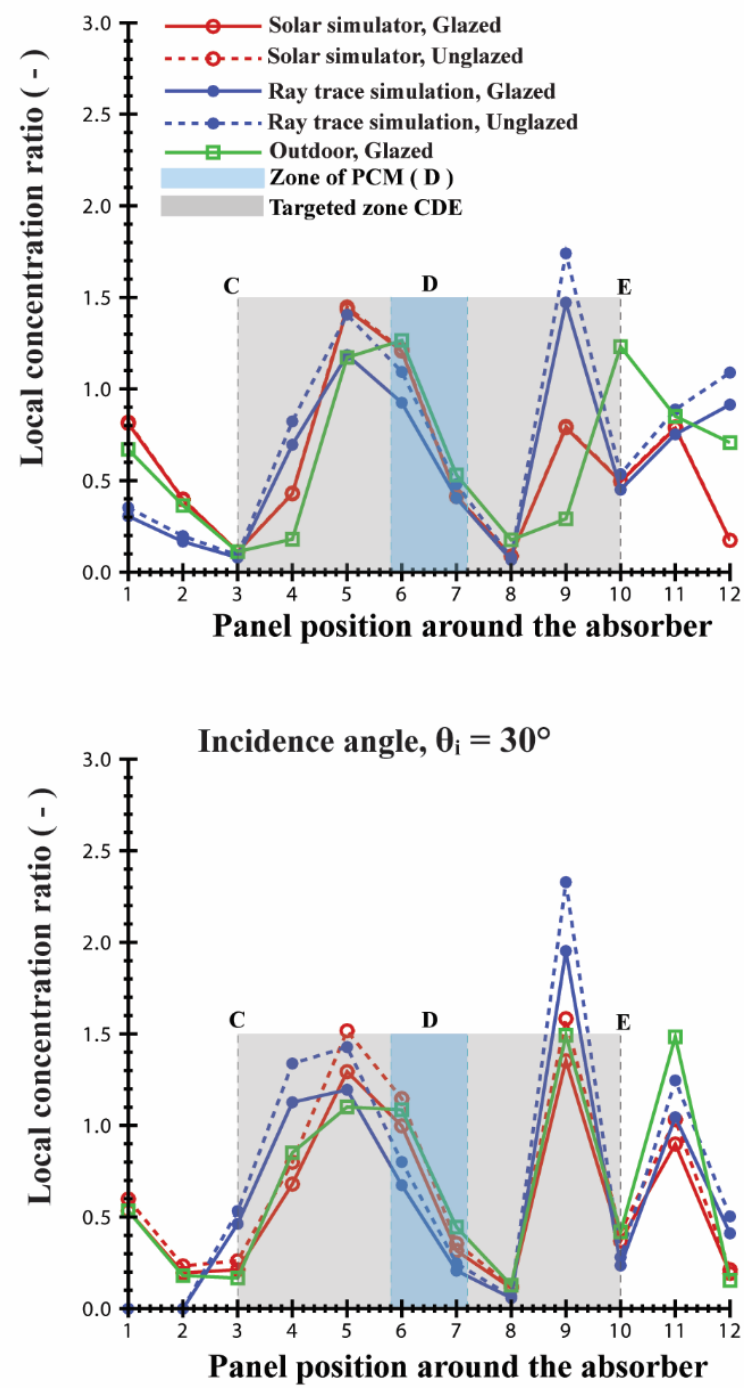

625 Fig. A. 1. Predictions of local concentration ratio around the absorber by ray tracing and 626 experimental (indoor and outdoor) methods for a glazed and unglazed AFRICaS prototype 627 (incidence angles $-15^{\circ}, 15^{\circ},-30^{\circ}$ and $30^{\circ}$ ). Also shown are the targeted zone CDE and the 628 zone of PCM. 
Incidence angle, $\theta_{\mathrm{i}}=-45^{\circ}$
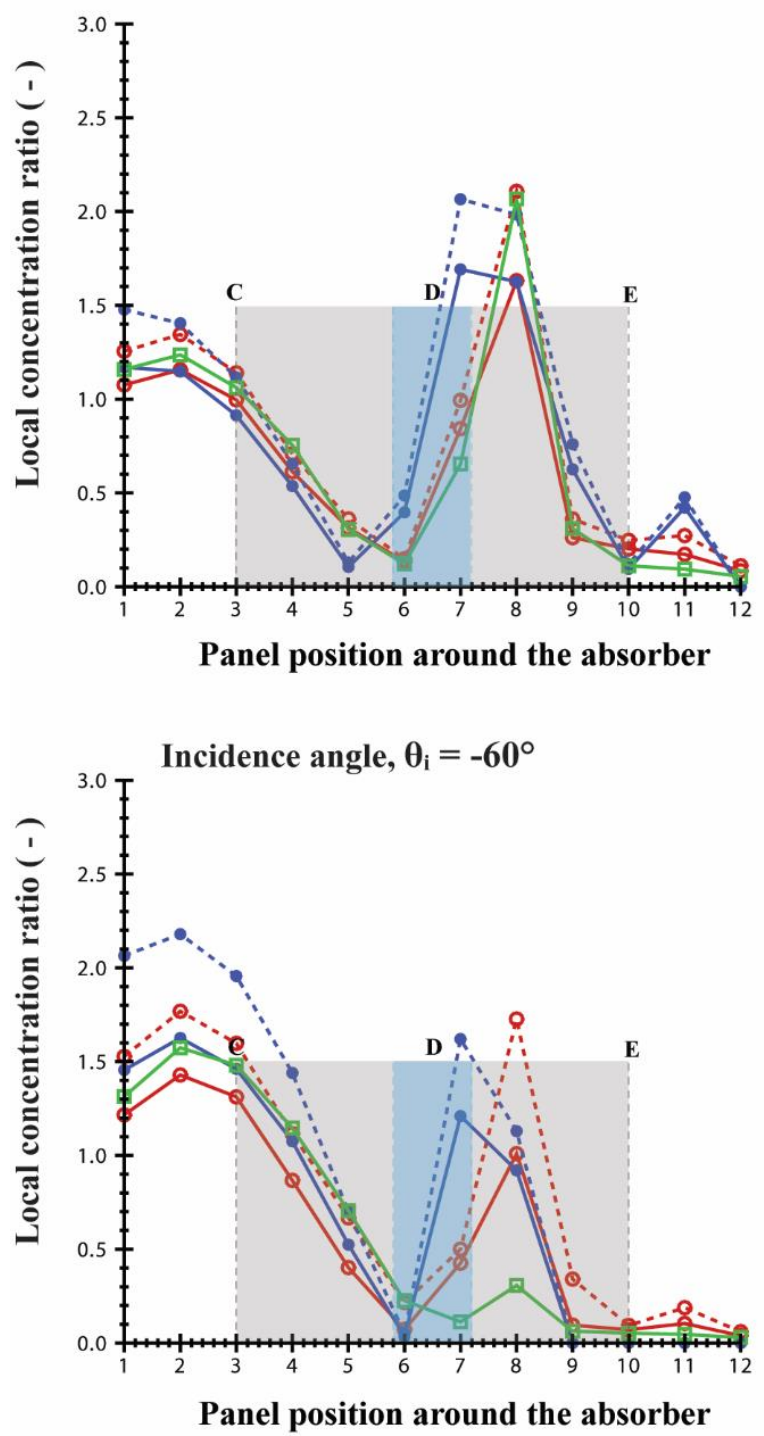

Incidence angle, $\theta_{\mathrm{i}}=45^{\circ}$
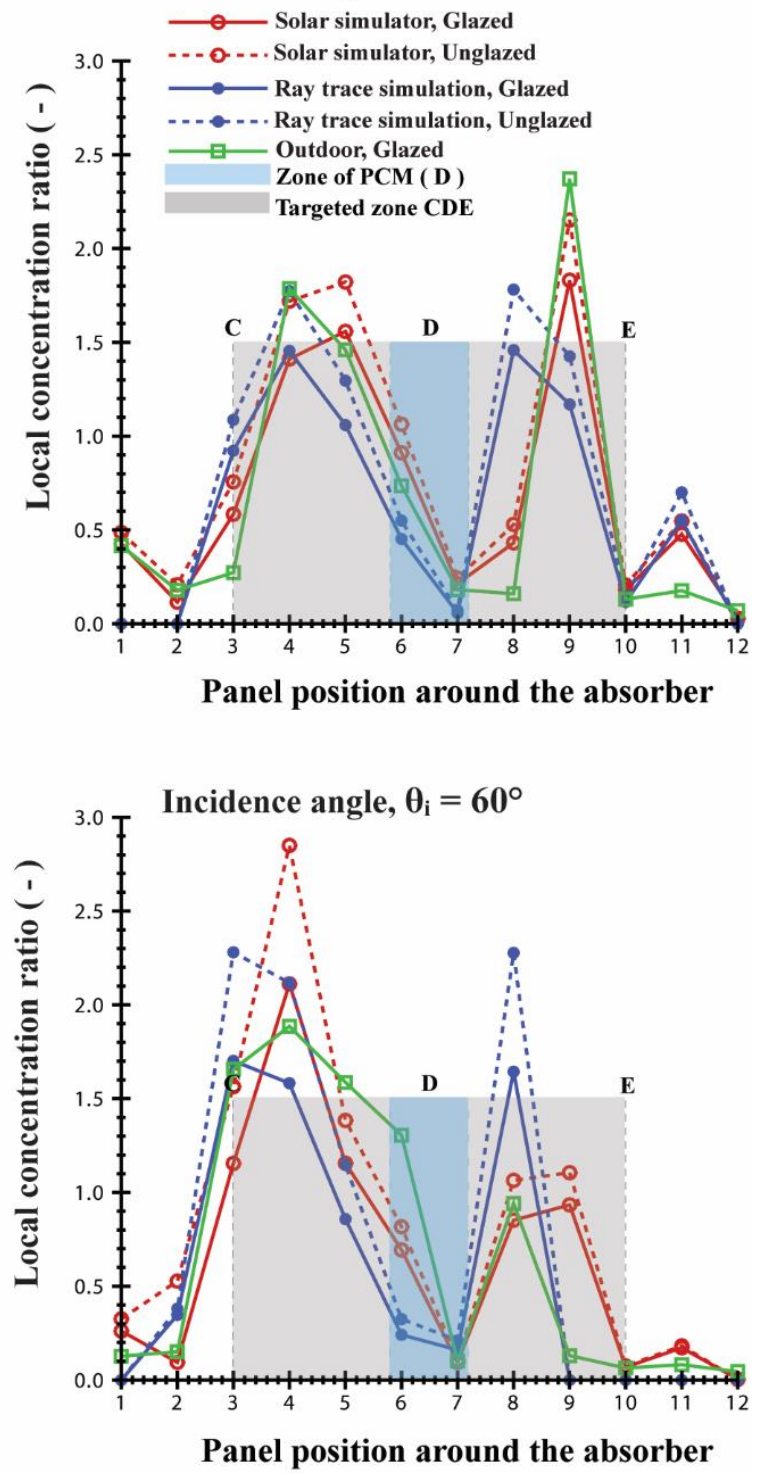

Fig. A. 2. Predictions of local concentration ratio around the absorber by ray tracing and 631 experimental (indoor and outdoor) methods for a glazed and unglazed AFRICaS prototype 632 (incidence angles $-45^{\circ}, 45^{\circ},-60^{\circ}$ and $60^{\circ}$ ). Also shown are the targeted zone CDE and the 633 zone of PCM 
Adsten, M., Hellström, B., Karlsson, B., 2004. Measurement of radiation distribution on the absorber in an asymmetric CPC collector. Sol. Energy 76, 199-206. https://doi.org/10.1016/j.solener.2003.08.024

Alanod-Solar, n.d. Efficient solar solutions, MIRO-SUN® [WWW Document]. URL https://www.alanod.com/industries/solar/ (accessed 5.8.19).

Arya, F., 2014. Developing alternative sealing materials in fabrication of evacuated glazing at low temperature. Ulster University.

Arya, F., Moss, R., Hyde, T., Shire, S., Henshall, P., Eames, P., 2018. Vacuum enclosures for solar thermal panels Part 2: Transient testing with an uncooled absorber plate. Sol. Energy 174, 1224-1236. https://doi.org/https://doi.org/10.1016/j.solener.2018.10.063

Benitez, P., Hernandez, M., Mohedano, R., Minano, J.C., Munoz, F., 1999. New nonimaging static concentrators for bifacial photovoltaic solar cells, in: SPIE's International Symposium on Optical Science, Engineering, and Instrumentation. Denver, CO, United States, pp. 22-29.

Bhowmik, N.C., Kandpal, T.C., 1988. Optical flux mapping of a seasonally adjusted linear solar concentrator using a triangular absorber. Energy Convers. Manag. 28, 35-38. https://doi.org/10.1016/0196-8904(88)90008-8

Bruton, T., Mason, N., Roberts, S., Hartley, O.N., Gledhill, S., Femandez, J., Russell, R., Warta, W., Glunz, S., Schultz, O., Hermle, M., Willeke, G., 2003. Towards 20\% efficient silicon solar cells manufactured at $60 \mathrm{MWp}$ per annum, in: 3rd World Conference on Photovoltaic Energy Conversion, May 11-18. Osaka, Japan, pp. 899-902.

Chaves, J., 2016. Plane curves, in: Introduction to Nonimaging Optics. CRC Press, Boca Raton, pp. 697-747. https://doi.org/https://doi.org/10.1201/9781420054323

Daystar, n.d. DS-1000 PV I-V Curve Tracer (Daystar test equipment for photovoltaic systems) [WWW Document]. URL http://www.daystarpv.com/curvetracer.html (accessed 4.26.19).

Dirnberger, D., Blackburn, G., Müller, B., Reise, C., 2015. On the impact of solar spectral irradiance on the yield of different PV technologies. Sol. Energy Mater. Sol. Cells 132, 431-442. https://doi.org/10.1016/j.solmat.2014.09.034

Duffie, J.A., Beckman, W.A., 2013. Solar engineering of thermal processes, 4th ed. ed. John Wiley \& Sons, New Jersey.

Green, M.A., Chong, C.M., Sproul, A., Zolper, J., Wenham, S.R., 1988. 20\% efficient laser, burried contact silicon solar cells, in: 20th IEEE Photovoltaic Specialists Conference, 26-30 Sept. IEEE, Las Vegas, pp. 411-414.

Guichard, D., Keisler, H.J., Koblitz, N., 2019. Polar Coordinates, Parametric Equations, in: Calculus - Early Transcendentals. OpenTextBookStore, San Francisco, pp. 237-251.

Guiqiang, L., Gang, P., Yuehong, S., Jie, J., Riffat, S.B., 2013. Experiment and simulation study on the flux distribution of lens-walled compound parabolic concentrator compared with mirror compound parabolic concentrator. Energy 58, 398-403. https://doi.org/10.1016/j.energy.2013.06.027

Hadjiat, M.M., Hazmoune, M., Ouali, S., Gama, A., Yaiche, M.R., 2018. Design and analysis of a novel ICS solar water heater with CPC reflectors. J. Energy Storage 16, 203-210. https://doi.org/10.1016/j.est.2018.01.012

Hatwaambo, S., Hakansson, H., Nilsson, J., Karlsson, B., 2008. Angular characterization of low concentrating PV-CPC using low-cost reflectors. Sol. Energy Mater. Sol. Cells 92, 1347-1351. https://doi.org/10.1016/j.solmat.2008.05.008

Hiraki, H., Hiraki, A., Maeda, M., Takahashi, Y., 2012. Unique features of cylindrical type solar-module contrasted with plane or conventional type ones. J. Phys. Conf. Ser. 379, 
Horta, P., Osório, T., Collares-Pereira, M., 2016. Energy Cost Based Design Optimization Method for Medium Temperature CPC Collectors, in: Rajpaul, V., Richter, C. (Eds.), SOLARPACES 2015: International Conference on Concentrating Solar Power and Chemical Energy Systems, 13-16 October 2015. AIP Publishing, Cape Town, South Africa, p. 020011.

Joy, B., Philip, J., Zachariah, R., 2016. Investigations on serpentine tube type solar photovoltaic/thermal collector with different heat transfer fluids: Experiment and numerical analysis. Sol. Energy 140, 12-20. https://doi.org/10.1016/j.solener.2016.10.045

Kalogirou, S.A., 2016. Nontracking solar collection technologies for solar heating and cooling systems, in: Wang, R.Z., Ge, T.S. (Eds.), Woodhead Publishing Series in Energy: Number 102. Advances in Solar Heating and Cooling. Woodhead Publishing, pp. 63-80. https://doi.org/10.1016/B978-0-08-100301-5.00004-7

Kreith, F., Krumdieck, S., 2013. Principles of sustainable energy systems, 2nd ed. Taylor \& Francis Group, Boca Raton.

Labouret, A., Villoz, M., 2010. Stand-alone photovoltaic generators, in: IET Renewable Energy Series 9 (English Translation): Solar Photovoltaic Energy. Institution of Engineering and Technology, London, pp. 268-274.

Li, Y., Grabham, N.J., Beeby, S.P., Tudor, M.J., 2015. The effect of the type of illumination on the energy harvesting performance of solar cells. Sol. Energy 111, 21-29. https://doi.org/10.1016/j.solener.2014.10.024

Ma, X., Zheng, H., Liu, S., 2019. A Review on Solar Concentrators with Multi-surface and Multi- element Combinations. J. Daylighting 6, 80-96. https://doi.org/10.15627/jd.2019.9

Madala, S., Boehm, R.F., 2017. A review of nonimaging solar concentrators for stationary and passive tracking applications. Renew. Sustain. Energy Rev. 71, 309-322. https://doi.org/10.1016/j.rser.2016.12.058

Muhumuza, R., Zacharopoulos, A., Mondol, J.D., Smyth, M., Pugsley, A., 2019a. Experimental study of heat retention performance of thermal diode Integrated Collector Storage Solar Water Heater (ICSSWH) configurations. Sustain. Energy Technol. Assessments 34, 214-219. https://doi.org/10.1016/j.seta.2019.05.010

Muhumuza, R., Zacharopoulos, A., Mondol, J.D., Smyth, M., Pugsley, A., Giuzio, G.F., Kurmis, D., 2019b. Experimental investigation of horizontally operating thermal diode solar water heaters with differing absorber materials under simulated conditions. Renew. Energy 138, 1051-1064. https://doi.org/10.1016/j.renene.2019.02.036

Norton, B., Eames, P.C., Yadav, Y.P., 1991. Symmetric and asymmetric linear compound parabolic concentrating solar energy collectors: The state-of-the-art in optical and thermo-physical analysis. Int. J. Ambient Energy 12, 171-190. https://doi.org/10.1080/01430750.1991.9675201

O'Gallagher, J.J., 2008. Nonimaging Optics in Solar Energy: Synthesis Lectures on Energy and the Environment: Technology, Science, and Society. Morgan \& Claypool Publishers, Flossmoor. https://doi.org/10.2200/S00120ED1V01Y200807EGY002

Paul, D.I., 2019. Optical performance analysis and design optimisation of multisectioned compound parabolic concentrators for photovoltaics application. Int. J. Energy Res. 43, 358-378. https://doi.org/10.1002/er.4271

Paul, D.I., Smyth, M., Zacharopoulos, A., Mondol, J., 2013. The design, fabrication and indoor experimental characterisation of an isolated cell photovoltaic module. Sol. Energy 88, 1-12. https://doi.org/10.1016/j.solener.2012.11.009

Prapas, D.E., Norton, B., Probert, S.D., 1987. Optics of parabolic-trough, solar-energy 
collectors, possessing small concentration ratios. Sol. Energy 39, 541-550. https://doi.org/10.1016/0038-092X(87)90061-2

Pugsley, A., Zacharopoulos, A., Mondol, J.D., Smyth, M., 2019. Theoretical and experimental analysis of a horizontal planar Liquid-Vapour Thermal Diode (PLVTD). Int. J. Heat Mass Transf. 144, 118660. https://doi.org/10.1016/j.ijheatmasstransfer.2019.118660

Rabl, A., 1976a. Comparison of solar concentrators. Sol. Energy 18, 93-111. https://doi.org/10.1016/0038-092X(76)90043-8

Rabl, A., 1976b. Optical and thermal properties of compound parabolic concentrators. Sol. Energy 18, 497-511. https://doi.org/10.1016/0038-092X(76)90069-4

Riveros, H.G., Oliva, A.I., 1986. Graphical analysis of sun concentrating collectors. Sol. Energy 36, 313-322. https://doi.org/10.1016/0038-092X(86)90149-0

Rohatgi, A., 2019. WebPlotDigitizer v4.2 [WWW Document]. URL https://automeris.io/WebPlotDigitizer (accessed 5.16.19).

Sarmah, N., Richards, B.S., Mallick, T.K., 2011. Evaluation and optimization of the optical performance of low-concentrating dielectric compound parabolic concentrator using raytracing methods. Appl. Opt. 50, 3303. https://doi.org/10.1364/ao.50.003303

Simon, A., Kalinka, G., 2005. Investigation of charge collection in a silicon PIN photodiode. Nucl. Instruments Methods Phys. Res. Sect. B Beam Interact. with Mater. Atoms 231, 507-512. https://doi.org/10.1016/J.NIMB.2005.01.108

Smyth, M., Eames, P.C., Norton, B., 1999a. A comparative performance rating for an integrated solar collector/storage vessel with inner sleeves to increase heat retention. Sol. Energy 66, 291-303. https://doi.org/https://doi.org/10.1016/S0038-092X(99)000274

Smyth, M., Zacharopoulos, A., Eames, P.C., Norton, B., 1999b. An experimental procedure to determine solar energy flux distributions on the absorber of line-axis compound parabolic concentrators. Renew. Energy 16, 761-764. https://doi.org/10.1016/S09601481(98)00274-2

Souliotis, M., Garoufalis, C.S., Vouros, A.P., Kavga, A., 2019. Optical study of twin-tanked ICS solar heaters combined with asymmetrical CPC-type reflectors. Int. J. Energy Res. 43, 884-895. https://doi.org/10.1002/er.4320

Souliotis, M., Quinlan, P., Smyth, M., Tripanagnostopoulos, Y., Zacharopoulos, A., Ramirez, M., Yianoulis, P., 2011. Heat retaining integrated collector storage solar water heater with asymmetric CPC reflector. Sol. Energy 85, 2474-2487. https://doi.org/https://doi.org/10.1016/j.solener.2011.07.005

Souliotis, M., Tripanagnostopoulos, Y., 2008. Study of the distribution of the absorbed solar radiation on the performance of a CPC-type ICS water heater. Renew. Energy 33, 846858. https://doi.org/10.1016/j.renene.2007.05.042

Tabor, H., 1984. Comment-The CPC concept-theory and practice. Sol. Energy 33, 629-630. https://doi.org/10.1016/0038-092X(84)90020-3

Theristis, M., Venizelou, V., Makrides, G., Georghiou, G.E., 2018. Energy yield in photovoltaic systems, 3rd ed, McEvoy's Handbook of Photovoltaics: Fundamentals and Applications. Elsevier Ltd, London. https://doi.org/10.1016/B978-0-12-8099216.00017-3

Tian, H., Mancilla-David, F., Ellis, K., Muljadi, E., Jenkins, P., 2012. A cell-to-module-toarray detailed model for photovoltaic panels. Sol. Energy 86, 2695-2706. https://doi.org/10.1016/j.solener.2012.06.004

Tian, M., Su, Y., Zheng, H., Pei, G., Li, G., Riffat, S., 2018. A review on the recent research progress in the compound parabolic concentrator (CPC) for solar energy applications. Renew. Sustain. Energy Rev. 82, 1272-1296. https://doi.org/10.1016/j.rser.2017.09.050 
Tripanagnostopoulos, Y., Souliotis, M., Nousia, T., 2002. CPC type integrated collector storage systems. Sol. Energy 72, 327-350. https://doi.org/10.1016/S0038092X(02)00005-1

Tripanagnostopoulos, Y., Yianoulis, P., 1992. Integrated collector-storage systems with suppressed thermal losses. Sol. Energy 48, 31-43. https://doi.org/10.1016/0038092X(92)90174-9

Tripanagnostopoulos, Y., Yianoulis, P., Papaefthimiou, S., Zafeiratos, S., 2000. CPC solar collectors with flat bifacial absorbers. Sol. energy 69, 191-203. https://doi.org/10.1016/S0038-092X(00)00061-X

UKAS, 2012. The Expression of Uncertainty and Confidence in Measurement, UKAS Publication. United Kingdom.

Ustaoglu, A., Alptekin, M., Okajima, J., Maruyama, S., 2016. Evaluation of uniformity of solar illumination on the receiver of compound parabolic concentrator (CPC). Sol. Energy 132, 150-164. https://doi.org/10.1016/j.solener.2016.03.014

Waghmare, S.A., Gulhane, N.P., 2016. Design and ray tracing of a compound parabolic collector with tubular receiver. Sol. Energy 137, 165-172. https://doi.org/10.1016/j.solener.2016.08.009

Widyolar, B., Jiang, L., Winston, R., 2017. Thermodynamic investigation of the segmented CPC, in: Kurtz, S.R., Winston, R. (Eds.), Nonimaging Optics: Efficient Design for Illumination and Solar Concentration XIV. SPIE, p. 16. https://doi.org/10.1117/12.2276711

Winston, R., 2016. How nonimaging optics began, in: Winston, R., Gordon, J.M. (Eds.), . International Society for Optics and Photonics, p. 995502. https://doi.org/10.1117/12.2239175

Yadav, P., Tripathi, B., Lokhande, M., Kumar, M., 2013. Effect of temperature and concentration on commercial silicon module based low-concentration photovoltaic system. J. Renew. Sustain. Energy 5. https://doi.org/10.1063/1.4790817

Yurchenko, V., Yurchenko, E., Ciydem, M., Totuk, O., 2015. Ray tracing for optimization of compound parabolic concentrators for solar collectors of enclosed design. Turkish J. Electr. Eng. Comput. Sci. 23, 1761-1768.

Zacharopoulos, A., 2001. Optical design modelling and experimental characterisation of lineaxis concentrators for solar photovoltaic and thermal applications. PhD Thesis: University of Ulster.

Zacharopoulos, A., Eames, P.C., McLarnon, D., Norton, B., 2000. Linear dielectric nonimaging concentrating covers for PV integrated building facades. Sol. Energy 68, 439452. https://doi.org/10.1016/S0038-092X(00)00013-X

Zacharopoulos, A., Eames, P.C., Norton, B., 1996. Optical analysis of a compound parabolic concentrator with four different absorber-envelope configurations, using a ray-trace technique, in: World Renewable Energy Congress (4th Renewable Energy, Energy Efficiency and the Environment: 15-21 June. Pergamon, Denver, CO, United States.

Zacharopoulos, A., Mondol, J.D., Smyth, M., Hyde, T., O’Brien, V., 2009. State-of-the-art solar simulator with dimming control and flexible mounting, in: Proceedings of the ISES Solar World Congress 2009: Renewable Energy Shaping Our Future, 11-14 October. International Solar Energy Society, Johannesburg, South Africa, p. 854.

Zacharopoulos, A., Paul, D.I., Smyth, M., Mondol, J., 2012. Optical characterisation of a PV concentrator under simulated and realistic solar conditions using an isolated cell PV module, in: Proceedings of the Eurosun2012 Conference, 18-20 September. Croatian Solar Energy Association, Opatija, Croatia, pp. 1-8. 